\title{
The volatility spillover effect of the European Union (EU) carbon financial market
}

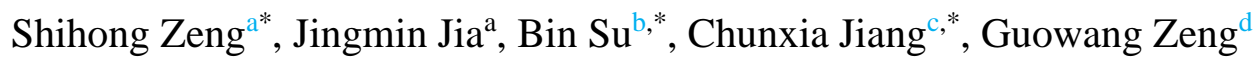

${ }^{a}$ College of Economics \& Management, Beijing University of Technology, Beijing 100124, China

${ }^{\mathrm{b}}$ Energy Studies Institute, National University of Singapore, Singapore 119620, Singapore

${ }^{\mathrm{c}}$ Business School, University of Aberdeen, Aberdeen, AB24 3QY, United Kingdom

${ }^{\mathrm{d}}$ Department of Business and Management, LUISS University, Rome 00197, Italy

\section{*Corresponding authors}

College of Economics \& Management, Beijing University of Technology, Beijing 100124, China, E-mails: zengshihong2000@aliyun.com (S. Zeng); Energy Studies Institute, National University of Singapore, Singapore 119620, Singapore, E-mails: subin@nus.edu.sg (B.Su); Business School, University of Aberdeen, Aberdeen, AB24 3QY, United Kingdom, E-mails:

chunxia.jiang@abdn.ac.uk (C. Jiang) 


\begin{abstract}
This paper modifies the BEKK-GARCH model based on the empirical results of the VAR model to analyze the dynamic volatility spillover effect between the European Union allowance (EUA) and certified emissions reduction (CER) markets during the second and third phases of the European Union Emission Trading System (EU ETS). The empirical results show that (1) an asymmetric volatility spillover effect exists between the EUA and CER markets and that the EUA market has a more significant volatility spillover effect on the CER market, and (2) the volatility spillover effect between the EUA and CER becomes weaker in phase III since the European Commission has limited the substitution of CER for EUA more strictly and the global carbon reduction requirements have become less demanding. Our study can help investors and managers of carbon market to have a more comprehensive understanding of the information and risk transmission mechanism between the EUA and CER markets, thus, providing them with a basis make investment decisions and formulate policies.
\end{abstract}

Keywords: Carbon financial market; Volatility spillover effect; VAR model; BEKK-GARCH model

JEL classification codes: G140; G150; Q540 


\section{Introduction}

The economic development of countries is strongly correlated with their energy consumption level (Rajalingam and Srivastava, 2020). In recent years, with the rapid economic growth of countries, an increasing level of energy consumption has led to a large number of greenhouse gas emissions, and resulted in abnormal climate and ecological changes. Therefore, climate change has become a challenge to which people are paying ever-increasing attention (Feria-Domínguez et al., 2018; Zeng et al., 2017), and a low-carbon economy has become an important target worldwide. Since December 1997, the Kyoto Protocol has required industrialized countries to sign greenhouse gas (or carbon) reduction agreements. Under the protocol's restrictions, carbon dioxide emission rights have become new assets that differ from both commodity futures and financial assets (Medina and Pardo, 2013), ultimately forming a carbon finance (or trading) market dominated by carbon dioxide emissions rights.

Carbon markets are a globally accepted tool for climate change mitigation because they provide cost-efficient solutions (Sousa et al., 2014). To date, the most effective system is the EU ETS. The EU ETS assumes the form of a cap and trade as follows: companies can obtain EUA, the initial allocation of carbon emissions, free of charge according to certain criteria or pay by auction. Companies whose actual emissions fall below their allowance can sell EUA in the carbon market, and those that exceed their allowance must buy EUA. The EU ETS is divided into three phases. The first phase (2005-2007) focused on testing the EU ETS policies and systems. In the second phase (2008-2012), i.e., the Kyoto period, the participants expanded to 
countries outside Europe. During the third phase, which began in 2013 and will last until 2020, the auction method has been widely introduced.

The EU ETS not only trades in EUA but is also closely linked to global carbon reduction. The Clean Development Mechanism (CDM) proposed by the Kyoto Protocol is designed to encourage emission reductions by non-Annex I Parties. The core feature is the ability of a company to invest in CDM projects in non-Annex I countries to offset some of its carbon emissions by the amount of carbon reductions generated by the projects (CER). Therefore, CER can also be traded on the EU ETS market as a carbon offset. However, the offset of the CER has been criticized (Kamdem et al., 2016; Nazifi, 2013) since CER reduces the market price of EUA, i.e., the cost of the enterprise to emit carbon dioxide, and undermines efforts to reduce emissions in Europe. Therefore, starting from the second phase, the European Commission stipulated that the average amount of CER used by enterprises covered by EU ETS shall not exceed 13.4\% of the total allowance. During the third phase, only the CER from the least developed regions that is accepted by all EU Member States can be used as a substitute for EUA.

Studying the relationship between EUA and CER markets is significant. On the one hand, CER can replace EUA to some extent to fulfill the commitment to reduce carbon emissions; thus, market participants may find arbitrage opportunities between the two markets, thereby influencing the related structure of carbon prices in the market (Kanamura, 2016). On the other hand, the prices of EUA and CER respectively represent the European carbon market price and world carbon price (Chevallier, 2011). Some basic factors influencing carbon price, such as energy price, weather, and 
policies have an impact on the EUA and CER markets, resulting in a linkage effect between them. Therefore, studying the relationship between the EUA market and CER market can not only help the market managers and investors understand the rules of the EU ETS market, but also assist them in understanding the mechanism of information flow and risk transfer between the European carbon market and other carbon markets in the world. Consequently, such efforts may reduce the investment risks of EU ETS, and make contributions to promote the global carbon emission reduction.

Some scholars have studied the relationship between the EUA and the CER market. For example, Chevallier (2010b) and Koop and Tole (2013) have both confirmed the causal relationship between the EUA market and CER market, and found that the EUA market plays a dominant role in their relationship. However, at present, most studies on the relationship between EUA and CER markets focus on the return spillover effect, that is, the information transmission relationship between returns, while few studies on volatility spillover effect, that is, the information transmission relationship between volatilities or risks.

Since the establishment of the carbon market, its price has changed dramatically, and there are more uncertainties and higher risks in the carbon market compared with the traditional financial market (Chai \& Zhou, 2018; Zhu et al., 2020). Therefore, exclusively analyzing the return spillover effect cannot help us fully understand the relationship between the carbon market and other markets. It is necessary to study the volatility spillover effect of the carbon market in order to better grasp its mechanism of information and risk transmission. Many scholars have 
conducted research on the volatility spillover effect of the carbon market. For example, Reboredo (2014) studies the volatility spillover effect between the oil market and the EU carbon market. Zhang and Sun (2016) study the time-varying relationship and the volatility spillover effect between EU carbon allowance futures prices and energy prices. Wu et al. studies the volatility spillover effects between the EU carbon emission rights market and three energy futures markets (crude oil, natural gas, and coal). Most of these studies have confirmed the volatility spillover effect between the carbon market and the energy market. Unlike these studies, our main objective is to explore the volatility spillover effects between different carbon markets within the EU ETS and to extend the research to the third phase of the EU ETS.

Although the existing literature has found that the correlation between EUA and CER markets is time-varying (Chevallier, 2011; Kamdem et al., 2016), most studies related to EUA and CER markets have examined the second phase of EU ETS. After the EU ETS entered phase III, scholars have not studied whether the changes in policies and international carbon emission reduction environment would affect the relationship between EUA and CER. Instead, this paper pays special attention to the following questions: (1) is there any volatility spillover effect on the EUA and CER markets? If so, is this effect between the two markets symmetrical? (2) Will the relationship between EUA and CER market, especially the risk transmission mechanism, change as EU ETS enters the third phase?

To answer these questions, we first study the impacts that different phases of EU ETS have 
on the carbon market structure. Generally, the event study is widely used to study the impact of policies or special events on market returns (Fan et al., 2017; Seyedimany, 2019). However, the event study is only applicable to the short-term effects of events. In this paper, we adopt the Unit root test with structural breaks to discuss the impact of policies and environmental changes in different phases of the EU ETS on the market structure of EUA and CER. The results show that Phase III of the EU ETS has an impact on the structure of EUA and CER markets with a four-month delay, thus, ignoring the structural breaks might lead to invalid conclusions (Salisu and Oloko, 2015).

Then, we analyze the changes in volatility spillover effects between the EUA and CER markets in different phases according to the structural break dates. The GARCH-BEKK model is a very useful method for analyzing volatility spillover effects. It can not only ensure the positive definiteness of the covariance matrix, minimize the number of parameters that need to be estimated, but also capture a market's volatility spillover effects on itself and on other markets at the same time. Therefore, this paper adopts the GARCH-BEKK model for our research. In order to make the results more accurate, we refer to the method of Agren (2006). We first use the VAR model to study the return spillover effect between the EUA market and CER market, and then modify the BEKK-GARCH model to study the volatility spillover effect between the EUA and CER markets based on the empirical results of the VAR model. In general, our study finds that there is an asymmetric volatility spillover effect between the EUA and CER markets. Furthermore, the relationship between these two markets weakens in the third phase of the EU ETS. That is to 
say, the strict restrictions on the use of CER by the European Commission and the decrease in carbon emission reduction pressure among countries have made the EUA and CER markets more fragmented.

Our study makes up for the lack of research on the development of EU ETS in the third phase among the existing studies. Moreover, it provides timely, effective, and practical insights as well as policy implications for investors and government managers. From a pragmatic perspective, this paper can help investors improve their abilities to predict carbon market risks, thereby reducing their investment risks. In terms of policies, this article can help carbon market managers fully understand the mechanism of information and risk transmission between the EUA market and CER market, and recognize the impact that changes in policies have on the correlation between these two markets, providing references for future policy-making.

Our study can also provide experience and a reference for other carbon emissions trading systems. The EU ETS was established early and is not only the largest but also the most mature carbon emissions trading system. The price changes of EU ETS products are similar to global economic indicators (Gürler et al., 2016) and play an important role in the market pricing of international carbon credits. Worldwide, some countries are actively establishing carbon finance markets to achieve emission reductions. For example, China has established seven carbon emission trading pilots and launched the Chinese Certified Emission Reduction (CCER) to offset carbon emissions. Studies investigating the volatility spillovers of EUA and CER in the EU carbon market can help those countries build a more efficient carbon market. 
The contributions of this paper are as follows: first, we extend studies related to the volatility spillover effects between the EUA and CER markets to the third phase of the EU ETS. The results show that after EU ETS entered the third phase, changes in policies and the international carbon emission reduction environment not only changed the structure of the EUA and CER markets, but also had an impact on the relationship between EUA and CER markets. In the phase III of the EU ETS, the European Commission's strict restrictions on the use of CER led to the weakening of the volatility spillover effect between the EUA market and CER market. Furthermore, we modify the BEKK-GARCH model based on the empirical results of the VAR model, and verify the reliability of the estimated results through robustness tests, which contribute to the study of spillover effects in the carbon market.

The structure of this paper is as follows: section 2 provides a review of previous research; section 3 describes the theoretical models and the data used; section 4 shows the empirical results; and section 5 presents the conclusions and implications.

\section{Literature review}

\subsection{External correlation of EU carbon financial markets}

Scholars have studied the EU ETS and conducted numerous empirical analyses of the factors related to the EU carbon emissions rights market. These scholars believe that many factors are associated with the price of carbon emissions rights, including energy demand and 
price, external environment and policy decision.

Dutta (2018) studies the influence of oil market uncertainty on EUA price volatility by improving the EGARCH model, and found that the influence of crude oil volatility index on EUA market is asymmetric. Uddin et al. (2018) use typical c-vine copula and c-vine conditional value-at-risk (CoVaR) models to find that carbon assets can provide diversified benefit for investment in energy commodities, such as crude oil, natural gas, ethanol, heating oil, coal and gasoline. Hammoudeh et al. (2015) use a nonlinear autoregressive distributed lag (NARDL) model to find that carbon prices are affected by the prices of crude oil, natural gas, coal and electricity. Balcilar et al. (2016) use MS-DCC-GARCH model to find time-varying cross-market correlations and volatility spillover effects between EU carbon futures prices and electricity, coal and natural gas futures prices. Conrad et al. (2012) study the price of EUA at high-frequency with the GARCH model and find that it is affected by the decisions of the European Commission. Tang et al. (2017) find that the market mechanism and external environment are the main factors influencing the price fluctuations of the EUA and CER.

\subsection{Internal correlation of EU carbon financial markets}

The factors affecting the price of carbon trading rights include not only external factors but also the interactions between different markets within the carbon trading market, including carbon futures, spot markets and EUA and CER markets. Many scholars have conducted research investigating these internal interactions. 
Regarding studies related to the spillover effects of EUA futures and spot, Chevallier (2010a) finds that there is cointegration between EUA spot and futures when structural breaks are not considered. Rittler (2012) uses high-frequency (i.e., 10- and 30-minute frequency) data to study the EUA market and finds that the futures market plays a leading role in the price discovery process. He also finds volatility spillover effects from futures to the spot market.

Regarding studies investigating the relationship between EUA and CER markets, some scholars have studied the factors influencing the price difference between EUA and CER. Nazifi (2013) identifies the factors that impact the dynamics of the price spread between EUAs and CERs by detecting the changes in their structural relationship and finds that the price inconsistency between the two markets is caused by the different market frameworks, access constrains on the use of CERs and the uncertainty associated with CERs. Kanamura (2016) finds that the EUA volume has an impact on EUA-sCER swap transactions by using inverse Box-Cox-type marginal abatement cost (MAC) curves and simple emissions reduction volume processes.

Some scholars have studied the interactions between EUA and CER. Mansanet-Bataller et al. (2011) study the price relationships between EUAs and CERs, and their central results show that the price differences between EUAs and CERs are mainly driven by EUA prices and market microstructure variables and less importantly by emissions-related fundamental drivers; the authors also find that EUAs are the leading factor in the price formation of sCERs. Koop and Tole (2013) model the spot and future prices of an EUA along with the price of a CER by using 
flexible multivariate time series methods that allow for time variation in the parameters and find evidence of contemporaneous causality among these three variables with EUA futures price playing a dominant role in driving this relationship. In addition, some studies have found that the relationship between EUA and CER changes over time. Chevallier (2011) uses a DCC-MGARCH model to analyze the dynamic correlation between EUAs and sCERs and finds that the correlation coefficient between the two markets changes dynamically over time in the range of $[0.01 ; 0.90]$. Kamdem et al. (2016) use the wavelet method to model the interactions between EUA and CER futures prices in Phase II and find that the co-movement between the two markets changes over time and frequency.

\subsection{Research methods of volatility spillover effects}

The concept of volatility spillover effect was first proposed by Ross (1989). He believed that the information flow between markets created variations in volatility. Therefore, relevant information can be derived from volatility changes, and market volatility plays a key role in information transmission. Theoretically, the volatility spillover effect quantifies the rate of information flow from one market to another (Shen et al., 2018), and the direction of volatility spillover represents the direction of information flow. Specifically, if market A has a volatility spillover effect on market B, the information on market A (such as shocks and price volatilities) will be transmitted to market $\mathrm{B}$, contributing to price volatilities in market $\mathrm{B}$. On the other hand, from the perspective of modern finance, volatility represents the risk of assets. Therefore, the 
essence of volatility spillover effect is the transmission of risks between markets.

Many scholars have conducted research related to the volatility spillover effects of various markets, especially financial markets. These scholars use a variety of research methods, including the VAR model, the GARCH model, the copula model and wavelet analyses.

Diebold and Yilmaz (2012) propose a measure for studying volatility spillover effects based on forecast error variance decomposition (FEVD) from a generalized VAR model. This method is used to analyze the volatility spillover effect of the US asset market. Nazlioglu et al. (2013) study the fluctuating conduction mechanism between oil and agricultural commodities (i.e., corn, soybean, wheat, and sugar) by using the variance causality test and impulse response functions before and after the food crisis.

There are many types of GARCH models. Hegerty (2016) uses a multivariate GARCH analysis to examine the spillover effects of important commodity prices and outputs, exchange rates, interest rates, and inflation in major emerging markets. Green et al. (2018) investigate volatility spillovers to electric power from large exogenous shocks in the prices of gas, coal, and carbon emissions allowances in the German energy market by using a general VAR-BEKK model and the volatility impulse response function methodology. Sarwar et al. (2019) investigate the volatility spillover effect between stock market returns and crude oil returns in the top three Asian oil-importing countries by using the BEKK-GARCH, DCC-GARCH, cDCC-GARCH and GO-GARCH estimation techniques.

Wavelet theory is a powerful mathematical tool used for time series analyses. In recent 
years, Wavelet theory has attracted the attention of many scholars. Khalfaoui et al. (2015) combine the bivariate GARCH-BEKK model with a wavelet multiresolution analysis to capture the multiscale features of the mean and volatility spillovers between time series. Sousa et al. (2014) characterize the interrelation among $\mathrm{CO}_{2}$ prices, energy prices (electricity, gas and coal) and economic activity by using a multivariate wavelet analysis, which operates in the time frequency domain. Nasreen et al. (2020) study the dynamic linkages between oil price and stock indices of clean energy and technology companies by using wavelet coherency, phase differences and spillover analysis. Additionally, the copula model is often combined with other methods to study the volatility spillover effects. Uddin et al. (2018) model the multivariate tail dependence structure and spillover effects across energy commodities, such as crude oil, natural gas, ethanol, heating oil, coal and gasoline, with c-vine copula and CoVaR models. Yu et al. (2019) use the copula and VAR-BEKK-GARCH models to study the volatility spillovers between the oil and stock markets.

\subsection{Review of the research status and hypothesis testing}

The EU carbon finance market is an emerging market that is not yet fully mature. Therefore, scholarly research related to such a market mostly addresses influencing factors or market effectiveness. The energy commodity market is mainly related to the EU ETS market, and external environment and policy factors also affect the prices of the EU ETS.

In internal EU research investigating the carbon finance market, scholars mainly study 
the interactions between futures and spot in the EUA market and the relationship between the EUA market and CER market. The results show that EUA and CER markets have spillover effects and that EUA is in a dominant position in this relationship. In addition, Chevallier (2011) and Kamdem et al. (2016) find that the correlation between the EUA and CER markets is time-varying. However, most studies are limited to the second phase of the EU ETS.

Based on previous studies, this paper analyzes the volatility spillover effects of the EUA and CER markets during the second and third phases of EU ETS and proposes the following hypotheses:

Hypothesis 1: There are volatility spillover effects between the EUA and CER markets in phase II, and the EUA market plays a dominant role in the relationship between the two markets.

Hypothesis 2: The third phase of EU ETS has an impact on the relationship between the EUA and CER markets. In phase III, the volatility spillover effects of EUA and CER weaken or even disappear.

Our assumptions are realistic. According to the policy of the European Commission, CER can replace EUA to some extent but not completely. Therefore, the assumptions that there are volatility spillover effects between the two markets and that the EUA market is in a dominant position are reasonable. However, in phase III, the European Commission has restricted the substitution of CER for EUA more strictly, only CER from the least developed areas can be used as a substitute for EUA. Therefore, we believe that the volatility spillover effect between EUA 
and CER will weaken in phase III.

To test whether the hypothesis is correct, we used the breakpoint unit root test, VAR model and BEKK-GARCH model, which is modified based on the empirical results of the VAR model, to analyze the volatility spillovers between the EUA and CER markets during the second and third phases of the EU ETS.

\section{Methodology and data}

\subsection{Breakpoint unit root test}

There are two types of stability tests for a time series containing structural breakpoints. The first type is the IO Test (innovational outlier test), which assumes that the occurrence of structural breaks is a gradual process. The second type is the AO Test (additive outlier test), which assumes that structural breaks occur instantaneously. In this paper, we use the IO Test, assuming that the series with a trend and intercept has an intercept breakpoint. The test equation is as follows:

$\mathrm{y}_{\mathrm{t}}=\mu+\beta \mathrm{t}+\theta \mathrm{DU}_{\mathrm{t}}\left(\mathrm{T}_{\mathrm{b}}\right)+\omega \mathrm{D}_{\mathrm{t}}\left(\mathrm{T}_{\mathrm{b}}\right)+\rho \mathrm{y}_{\mathrm{t}-1}+\sum_{\mathrm{i}=1}^{\mathrm{k}} \mathrm{c}_{\mathrm{i}} \Delta \mathrm{y}_{\mathrm{t}-\mathrm{i}}+\mathrm{u}_{\mathrm{t}}$

where $\mathrm{DU}_{t}\left(\mathrm{~T}_{\mathrm{b}}\right)$ is an intercept break variable. $\mathrm{DU}_{t}\left(\mathrm{~T}_{\mathrm{b}}\right)=1$ if $\mathrm{t} \geq \mathrm{T}_{\mathrm{b}}$ and 0 otherwise. $\mathrm{D}_{t}\left(\mathrm{~T}_{\mathrm{b}}\right)$ is a one-time break dummy variable. $\mathrm{D}_{t}\left(\mathrm{~T}_{\mathrm{b}}\right)=1$ if $\mathrm{t}=\mathrm{T}_{\mathrm{b}}$ and 0 otherwise. $\mathrm{k}$ represents the lag order, which is determined according to the Schwarz criterion (SC) to correct the possible 
autocorrelation in the time series. The t-statistic for the estimated value of parameter $\rho$ is used

for testing the null hypothesis that $\mathrm{t}_{\widehat{\rho}}(\hat{\rho}=1)$, indicating that $\mathrm{y}_{\mathrm{t}}$ is notstationary, versus the alternative hypothesis that $t_{\hat{\rho}}(\hat{\rho}<1)$, indicating that $y_{t}$ is stationary. $T_{b}$ is the structural breakpoint date, and the date that maximizes the $t$ statistic of the intercept break variable $\left(t_{\widehat{\theta}}\right)$ is selected as the date of the structure breakpoint.

\subsection{VAR model}

The VAR model essentially examines the dynamic interactions among multiple variables and has been widely used (Arouri et al., 2012; Cummins, 2013). Its general form is as follows:

$\mathrm{R}_{\mathrm{t}}=\mu_{\mathrm{t}}+\Phi_{1} \mathrm{R}_{\mathrm{t}-1}+\Phi_{2} \mathrm{R}_{\mathrm{t}-2}+\cdots+\Phi_{\mathrm{p}} \mathrm{R}_{\mathrm{t}-\mathrm{p}}+\varepsilon_{\mathrm{t}}$

where $R_{t}$ is a $2 \times 1$ vector of the EUA and CER market returns and $\mu_{\mathrm{t}}$ is a $2 \times 1$ vector of constants. $\Phi_{i}, i=1, \ldots, p$ are $2 \times 2$ matrices of the coefficients, and $\varepsilon_{t}$ is a $2 \times 1$ vector of the error terms.

It is necessary to determine whether the entire VAR model is applicable according to the stable condition of the entire system, i.e., by calculating the value of the feature root polynomial. Comparing the calculated modulus of the inverse of the eigenvalue with 1 , if the modulo of the inverse of the eigenvalue is equal to 1 , the VAR model is not stable and needs to be re-established; if the modulus of the inverse of the eigenvalue is less than 1 , the VAR model is suitable. 


\subsection{BEKK-GARCH model}

This paper modifies the bivariate $\operatorname{BEKK}-\operatorname{GARCH}(1,1)$ model to study the volatility spillover effects of the daily return time series of the EUA and CER futures markets and reveals the direction of volatility spillovers and the information transmission paths in EU carbon financial markets.

The BEKK-GARCH model is a multivariate GARCH model originally proposed by Engle and Kroner (1995) that has been widely used to investigate volatility spillovers between markets (Wu and Li, 2013; Han et al., 2019). According to Agren (2006), the mean equation is modified based on the empirical results of the VAR model and is shown in section 4 . The conditional variance equation is as follows:

$\mathrm{H}_{\mathrm{t}}=\mathrm{CC}^{\prime}+\mathrm{A}^{\prime}\left(\varepsilon_{\mathrm{t}-1} \varepsilon_{\mathrm{t}-1}^{\prime}\right) \mathrm{A}+\mathrm{B}^{\prime} \mathrm{H}_{\mathrm{t}-1} \mathrm{~B}$

where $\varepsilon_{\mathrm{t}}=\left(\begin{array}{l}\varepsilon_{1 \mathrm{t}} \\ \varepsilon_{2 \mathrm{t}}\end{array}\right)$ is a $2 \times 1$ vector of the error terms from the mean equation and follows a normal distribution, $H_{t}=\left(\begin{array}{l}h_{11, t} h_{12, t} \\ h_{21, t} h_{22, t}\end{array}\right)$ is the conditional variance-covariance matrix, and $\mathrm{C}=$ $\left(\begin{array}{ll}c_{11} & 0 \\ c_{21} & c_{22}\end{array}\right)$ is the lower triangular matrix. $A=\left(\begin{array}{ll}a_{11} & a_{12} \\ a_{21} & a_{22}\end{array}\right)$ and $B=\left(\begin{array}{ll}b_{11} & b_{12} \\ b_{21} & b_{22}\end{array}\right)$ are both 2nd-order square matrices, and if $\mathrm{C}^{\prime} \mathrm{C}$ is positively definite, $\mathrm{H}_{t}$ is positive.

$\mathrm{h}_{11, \mathrm{t}}$ is the conditional variance of the first market, $\mathrm{h}_{22, \mathrm{t}}$ is the conditional variance of the second market, and $\mathrm{h}_{12, \mathrm{t}}$ is the conditional covariance between the two markets. The above three formulas represent the current market volatility. $a_{11}$ and $a_{22}$ in matrix A represent the $\mathrm{ARCH}$ effect of the sequence, which is used to represent the time-varying characteristics of the fluctuation. $b_{11}$ and $b_{22}$ in matrix $B$ represent the GARCH effect of the sequence, which is 
used to reflect the continuous characteristics of the fluctuation. $a_{12}$ and $a_{21}$ in matrix A refer to the impact conduction effects of different markets. $b_{12}$ and $b_{21}$ in matrix B refer to the wave conduction effect of different markets (also called the cross-wave effect). These two effects are collectively referred to as the volatility spillover effect.

We use the Wald test to test the volatility spillover effect between different markets; the null hypothesis is $a_{i j}=b_{i j}=0$, indicating that there is no volatility spillover from market $i$ to market $\mathrm{j}$, and the alternative hypothesis is $\mathrm{a}_{\mathrm{ij}}^{2}+\mathrm{b}_{\mathrm{ij}}^{2} \neq 0$, indicating that there is a volatility spillover from market $\mathrm{i}$ to market $\mathrm{j}$.

\subsection{Data description}

\subsubsection{Data selection and processing}

Having multiple exchanges, the EU ETS is currently the world's most extensive and highest volume carbon financial trading market. This paper selects the settle price of the continuous futures contract of the EUA and CER of the European Climate Exchange (ECX) as the sample data. Since the first phase of the EU ETS is experimental, and no CER futures products are introduced, this paper empirically studies only the volatility spillover effects of the second and third phases of the EU ETS.

We collected the EUA and CER futures prices from March 14, 2008 to July 27, 2017. We also consider the daily observations for the three-month Euribor rate, the Citi Economic Surprise 
Index and FTSE100 index as a reflection of the macro economy. In total, 2,445 sets of data were used as the research samples. If data are missing due to holiday breaks, this paper uses the data from the previous day to fix this problem. The sample size of the data in this paper is very large, which makes it more likely that we can draw conclusions that are close to the real situation. The data are derived from the Wind Economic Database, as shown in Table A.1.

The rate of return is an important indicator of price volatility, and its variance or standard deviation can be used to reflect the risk characteristics and volatility characteristics of a market. Compared with the price, the rate of return has more excellent statistical characteristics, rendering it more suitable for the empirical analysis in this paper. Therefore, to better study the volatility spillover effects of EUAs and CERs and overcome the problem that the price changes are too small, we study the characteristics of the market daily rate of return series, which is defined and calculated by the formula below:

$R_{t}=\left(\ln P_{t}-\ln P_{t-1}\right) * 100$

\subsubsection{Descriptive statistics and basic characteristics analysis}

To test the return rate series of the EUA and CER futures markets and their volatility characteristics, line charts of the prices and return rates of the two markets were plotted. In Figs. $1-4, \mathrm{RE}$ represents the return of EUA futures, and RC represents the return of CER futures. 


\section{EUA}

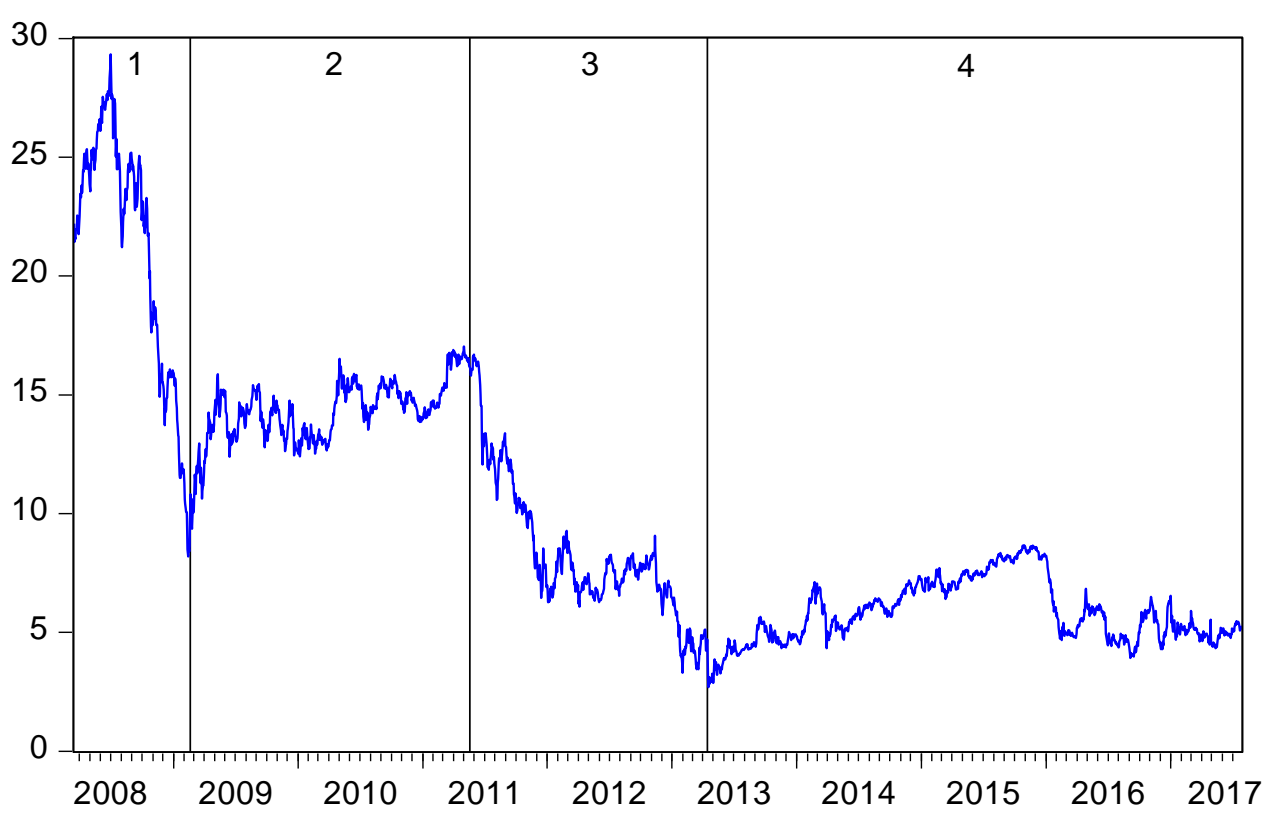

Fig. 1. Chart depicting the EUA futures market price.

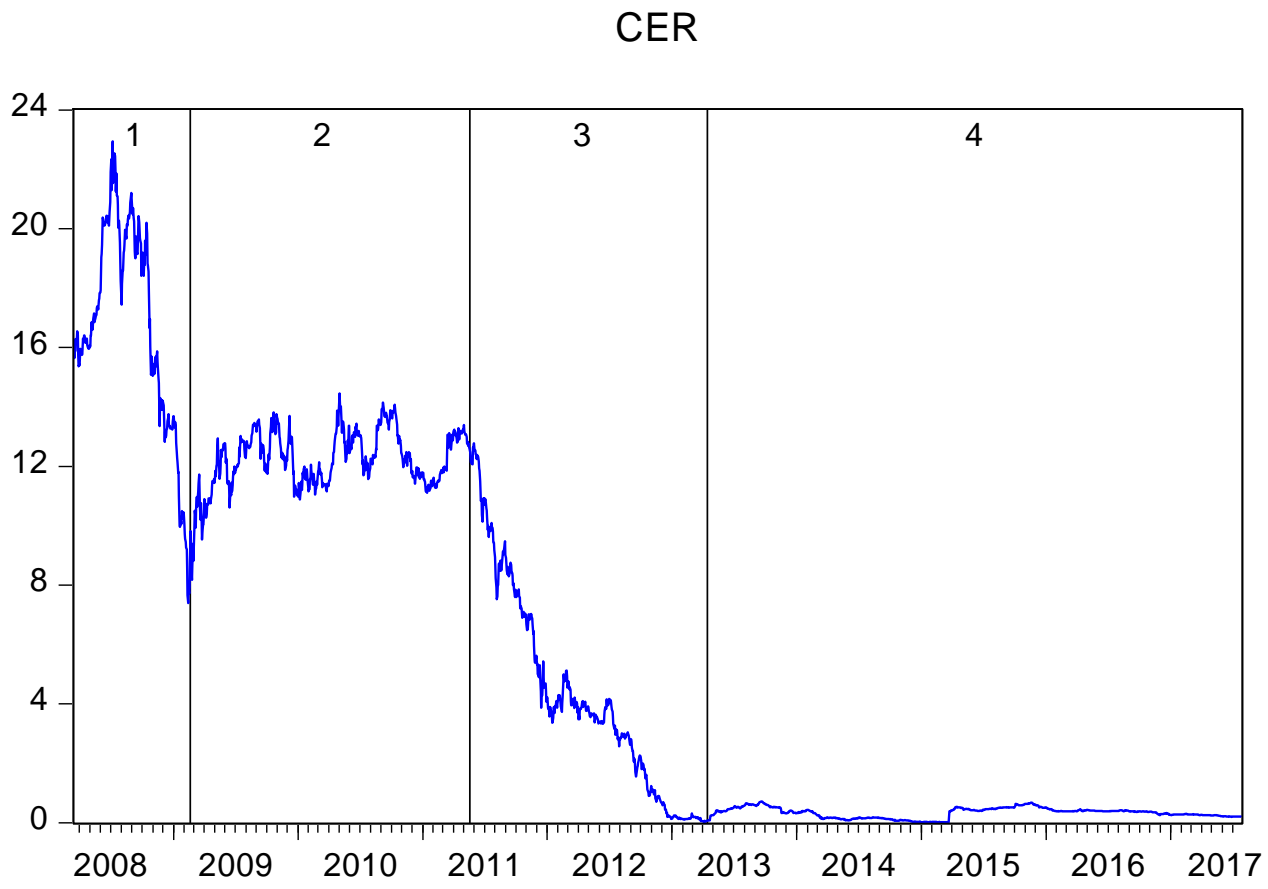

Fig. 2. Chart depicting the CER futures market price. 
RE

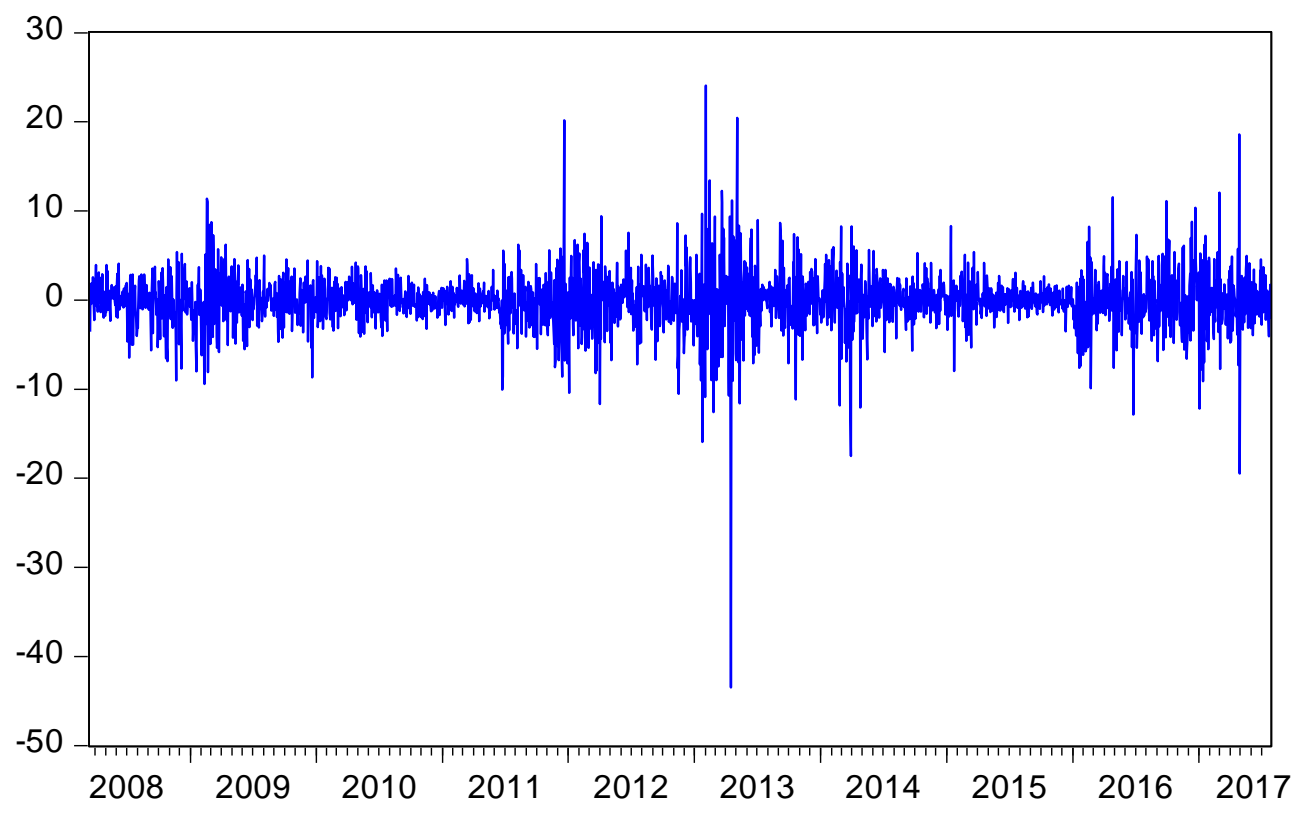

Fig. 3. Sequence diagram of the EUA futures market yield.

$\mathrm{RC}$

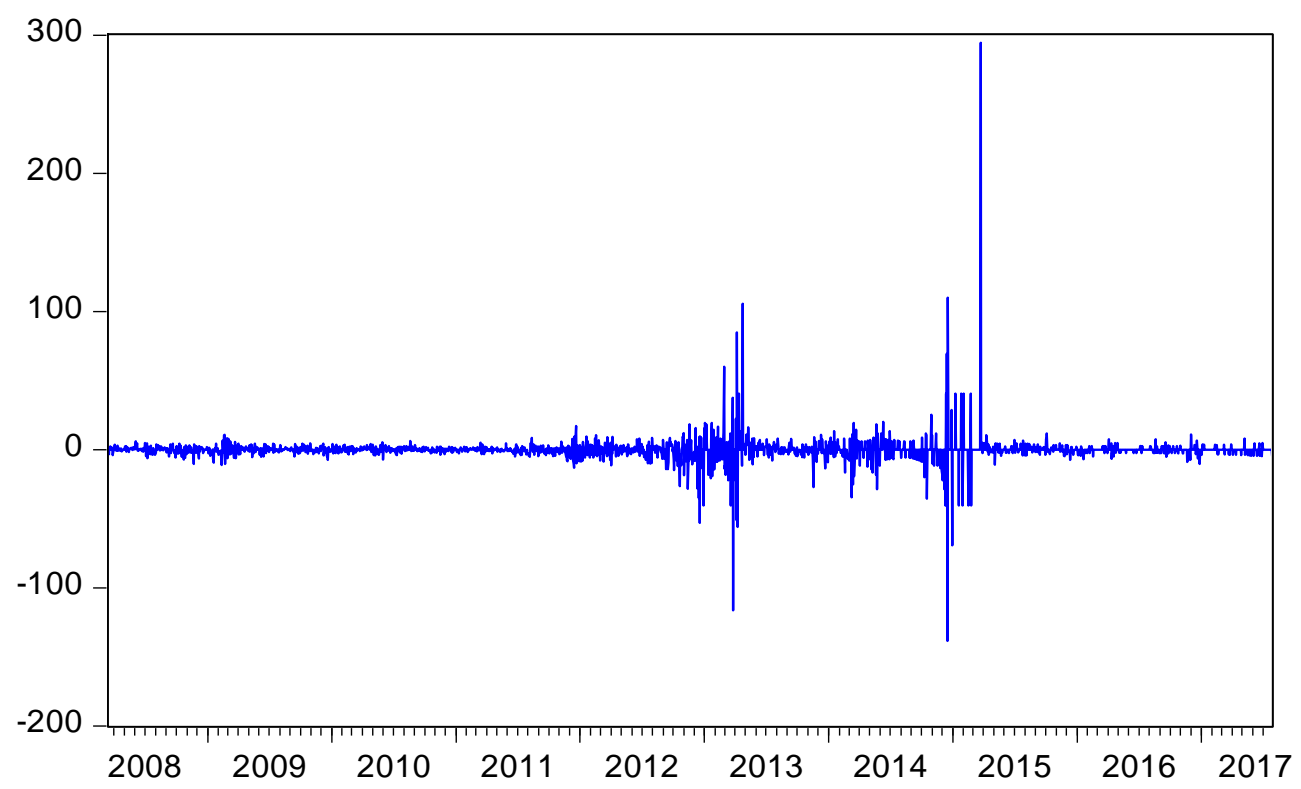


Fig. 4. Sequence diagram of the CER futures market yield.

We can perform a preliminary analysis based on the observed trend of EUA and CER prices and yields. As shown in Figs. 1 and 2, the price trend of EUA and CER is very similar. In quadrant 1, which spanned from March 2008 to February 2009, the prices of EUA and CER futures both underwent a process of first rising and then falling. Since June 2008, EUA futures prices have dropped from 29 euros to approximately 8 euros, while CER futures have dropped from 23 euros to approximately 7.5 euros. The drop in carbon prices in 2008 coincided with the global economic crisis, which not only strongly affected the real economy but also affected the carbon finance market. Due to the global economic recession caused by the financial crisis, the output of enterprises was reduced, and the carbon emission rights market was oversupplied, leading to a rapid decline in EUA and CER prices.

In quadrant 2, from February 2009 to May 2011, the futures prices of EUA and CER both recovered and stabilized within a reasonable range. The price of EUA futures fluctuated by approximately 14 euros, and the price of CER futures fluctuated by approximately 12 euros.

In quadrant 3, which spanned from May 2011 to April 2013, the outbreak of the European debt crisis contributed to the continuous downturn of the European economy, and the continuous decline in demand for carbon emission rights led to another collapse in the EUA and CER futures prices. The EUA futures fell to approximately 3 euros, while the CER futures fell even faster.

In quadrant 4, which represents data collected after 2013, the EU ETS begun its third 
phase. There are a large number of unused carbon emission rights in phase II because of the impact of the global economic crisis and the European debt crisis. Therefore, the European Commission allowed EUA and CER at the end of phase II to be transferred to phase III for interphase use, resulting in a continuous oversupply of carbon emission rights. In addition, the European Commission limited the use of CER in countries, such as China and India, in phase III. Therefore, in phase III, the prices of EUA and CER have not significantly recovered, and the prices of CER are still depressed.

As shown in Figs. 3 and 4, overall, the yield of CER futures market volatility is greater than that of the EUA futures market. The CER market has a greater level of uncertainty than the EUA market.

In basic data statistical analyses, the standard deviation reflects the degree of dispersion of financial assets in a certain period and is an evaluation index of the risk of financial assets. Skewness and kurtosis generally illustrate the normality of the yield as follows: skewness can indicate whether the distribution of the data is symmetrical, and kurtosis can indicate the shape of the data. The Jarque-Bera (JB) test is used to test whether the data follow a normal distribution. In addition, the Ljung-Box Q-statistics test and ARCH-LM test are used to test the significance of autocorrelation and $\mathrm{ARCH}$ effects, respectively.

Table 1 shows the basic characteristics of the EUA and CER futures market yield time series based on the results of the Ljung-Box Q-statistics test and ARCH-LM test. Based on the mean and standard deviation of the EUA and CER market returns, the EUA market has higher 
returns and smaller standard deviations, suggesting that it has strong profitability and low market risk. The EUA market yield series has a skewness of -0.85 and a kurtosis of 21.10 , indicating that the sequence has a "left-biased and high-thin" distribution pattern compared with a normal distribution (skewness is 0 , kurtosis is 3 ); the JB value is 33648.57 , which is significant at the $1 \%$ level. Therefore, the null hypothesis is rejected, i.e., the rate of return is nonnormally distributed. The skewness of the CER market yield series is 9.75 , and kurtosis is 384.17 , indicating that this sequence has a "right-biased and high-thin" distribution compared with a normal distribution; the JB value is 12171661 , which is significant at the $1 \%$ level. Therefore, the null hypothesis is rejected, i.e., the sequence is nonnormally distributed. The results of the Ljung-Box Q-statistics tests show that both EUA and CER market yield sequences have autocorrelation. In addition, the ARCH-LM tests reject the null hypotheses that there are no ARCH effects, indicating that both EUA and CER market yield sequences have ARCH effects.

Table 1. Basic characteristics of the EUA and CER futures market return rate

\begin{tabular}{lll}
\hline & RE & RC \\
\hline Mean & -0.0600 & -0.1801 \\
Maximum & 24.0515 & 294.4439 \\
Minimum & -43.4736 & -138.6294 \\
Std. Dev. & 3.2358 & 10.0130 \\
Skewness & -0.8470 & 9.7531 \\
Kurtosis & 21.0986 & 348.1736 \\
\hline
\end{tabular}




\begin{tabular}{lll}
\hline Jarque-Bera & $33648.57^{* * * *}$ & $12171661^{* * *}$ \\
LB-Q(15) & $64.1977^{* * *}$ & $192.7274^{* * *}$ \\
ARCH-LM & $16.2690^{* * *}$ & $3.3080^{* *}$ \\
\hline
\end{tabular}

Note: LB-Q(15) is the Ljung-Box Q-statistic for autocorrelation at lag 15. ARCH-LM is the F-statistic of the Lagrange multiple test for the ARCH effect with the lags set to $3 .{ }^{* * *}$ and $* *$ denote significance at the $1 \%$ and $5 \%$ levels, respectively.

\section{Empirical results and analysis}

\subsection{Breakpoint unit root test}

This paper uses the breakpoint unit root test to determine whether the EUA and CER market returns data are stable at level. The specific results are shown in Table 2. The test results show that the return rates of the EUA and CER futures markets are stable. In addition, if a structural break in the unit root equation is allowed, the break dates of the EUA and CER markets were both in April 2013, which is consistent with the time when the EU ETS entered phase III. Therefore, we can conclude that Phase III of the EU ETS had an impact on the structure of both the EUA and CER markets but with a four-month delay.

Table 2. Results of the unit root test with structural breaks

\begin{tabular}{lllll}
\hline Variables & t-statistic & $5 \%$ level & Break Date & Result \\
\hline
\end{tabular}




\begin{tabular}{lllll}
\hline RE & -37.4619 & -4.6435 & $4 / 18 / 2013$ & Stationary \\
RC & -36.3111 & -4.6435 & $4 / 04 / 2013$ & Stationary \\
\hline
\end{tabular}

In the following empirical study, the EUA and CER market yield sequence is divided into two samples based on the structural break dates. The first sub-sample, i.e., from March 14, 2008 to April 10, 2013, is regarded as the second phase of the EU ETS. In addition, the second sub-sample, i.e., from April 11, 2013 to July 28, 2017, is regarded as the third phase of the EU ETS.

\subsection{VAR analysis of the return spillover effect}

\subsubsection{Analysis of the VAR model results}

The choice of the number of lag periods has a significant impact on the VAR estimation as different lag periods could result in different analysis results. In general, when the order is large, the data can be free from the influence of error autocorrelation, and the market information can be accurately estimated; however, when the order is too large, the degree of freedom of the data is affected. According to the Akaike information criterion (AIC) and Schwarz criterion (SC), the lag order of the VAR model in phase II and phase III is both 2.

Fig. 5 shows the results of the AR root test of the VAR model in phase II; all characteristic roots are in the unit circle, indicating that the model is stable. Therefore, we can establish the VAR(2) model of the returns of the EUA and CER futures markets in phase II, and 
the results are shown in Table 3.

Table 3. Estimated results of the VAR(2) model in Phase II

\begin{tabular}{lll}
\hline & $\mathrm{RE}$ & $\mathrm{RC}$ \\
\hline $\mathrm{RE}(-1)$ & 0.0460 & 0.0713 \\
$\mathrm{RE}(-2)$ & {$[1.5355]$} & {$[1.1015]$} \\
& $-0.0694 * *$ & $-0.2704^{* *}$ \\
$\mathrm{RC}(-1)$ & {$[-2.3316]$} & {$[-4.1988]$} \\
& 0.0004 & $-0.2550^{* *}$ \\
$\mathrm{RC}(-2)$ & {$[0.0267]$} & {$[-8.6052]$} \\
& -0.0057 & $0.1087 * *$ \\
$\mathrm{C}$ & {$[-0.4164]$} & {$[3.6793]$} \\
SC & -0.1285 & $-0.5405^{* *}$ \\
AIC & {$[-1.5287]$} & {$[-2.9726]$} \\
\hline
\end{tabular}

Notes: The numbers in brackets are the empirical t-statistics of the estimated coefficients.

**denotes significance at the $5 \%$ level. 


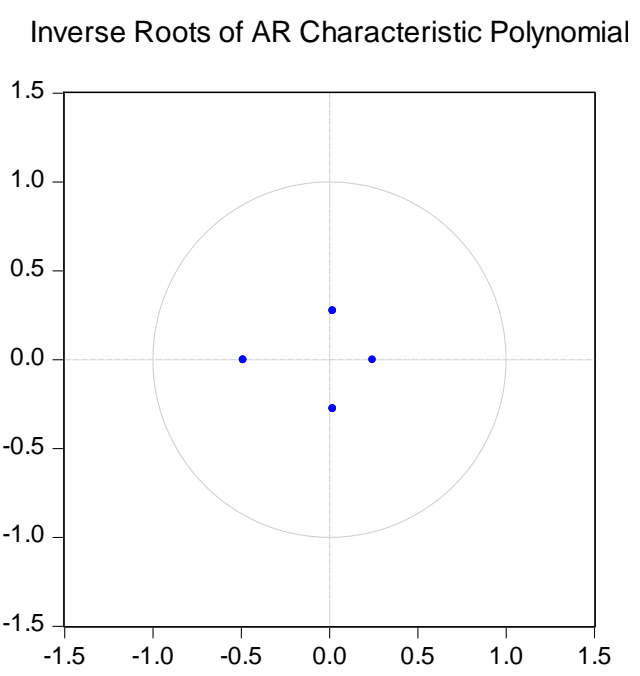

Fig. 5. Characteristic Root Test of the VAR(2) model in phase II.

In phase II, in the EUA market, the 2nd-order lag return rate of the EUA futures market has an impact on the current rate of return of $-0.07(\mathrm{~T}=-2.33)$, passing the significance test, and the coefficient is negative. The results show that the return in the second period before the EUA market could affect the current market returns in the opposite direction and indicates that the EUA futures market reflects information slowly. In the CER market, the 1st-order lag return rate of the CER futures market has an impact on the current return of $-0.26(\mathrm{~T}=-8.61)$, and the 2nd-order lag return rate has an impact on the current return of $0.11(\mathrm{~T}=3.68)$, both passing the significance test. These results show that the returns of the first two periods of the CER market could affect the current market returns. We also find that compared with the EUA futures market, the CER futures market reflects more information.

The 2nd-order lag return rate of the EUA futures market has an impact on the current 
return rate of the CER futures market of $-0.27(\mathrm{~T}=-4.20)$, passing the significance test and indicating that the CER market has an impact on the EUA market in the opposite direction. However, the impacts of all lag return of the CER market on the return EUA market do not pass the significance test, indicating that CER's return has no effect on EUA's return.

In summary, we find that there is a lead-lag relationship between the EUA market and CER market in phase II. Specifically speaking, the EUA market has a one-way return spillover effect on the CER market. The historical return of the EUA market has a significant negative impact on the return of the CER market, suggesting that high returns in the EUA market are more likely to lead to low returns in the CER market. This can occur because CER can partially replace EUA. When the EUA market has high return, investors in the carbon market will focus on it instead and reduce investments in the CER market, resulting in a decline in the liquidity and lower return of the CER market. Additionally, when the EUA market has a low return, the consequence is opposite. Our conclusion shows that in phase II, investors can use the return information on the EUA futures market to predict the price of CER futures market, indicating that EUA and CER markets are closely linked during this phase.

Fig. 6 shows the results of the AR root test of the VAR model in phase III. All characteristic roots are in the unit circle, indicating that the model is stable. Therefore, we can establish the VAR(2) model of the returns of the EUA and CER futures markets in phase III, and the results are shown in Table 4. 


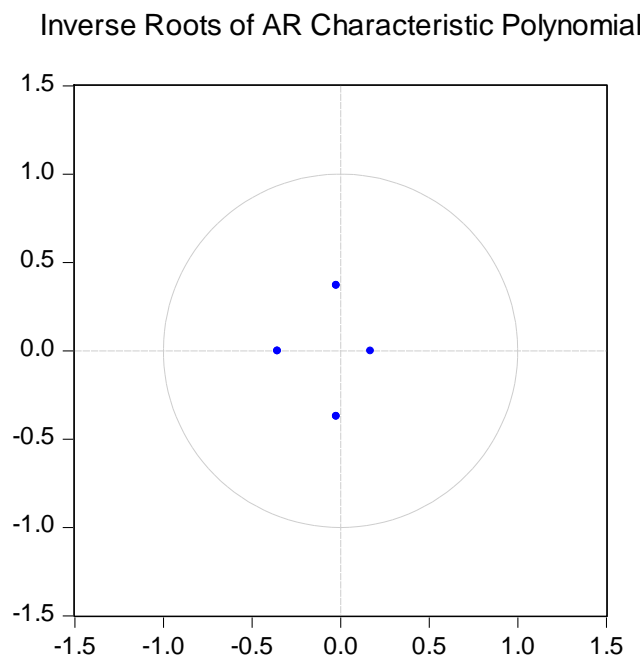

Fig. 6. Characteristic Root Test of the VAR(2) model in Phase III.

Table 4. Estimated results of the VAR(2) model in Phase III

\begin{tabular}{lll}
\hline & $\mathrm{RE}$ & $\mathrm{RC}$ \\
\hline $\mathrm{RE}(-1)$ & -0.0485 & -0.0612 \\
& {$[-1.6370]$} & {$[-0.5658]$} \\
$\mathrm{RE}(-2)$ & $-0.1392^{* *}$ & 0.0351 \\
& {$[-4.7001]$} & {$[0.3240]$} \\
$\mathrm{RC}(-1)$ & -0.0097 & $-0.1858^{* *}$ \\
$\mathrm{RC}(-2)$ & {$[-1.1809]$} & {$[-6.2136]$} \\
& -0.0043 & $0.0610 * *$ \\
L & {$[-0.5309]$} & {$[2.0500]$} \\
& 0.0129 & 0.1061 \\
\hline
\end{tabular}


Notes: The numbers in brackets are the empirical t-statistics of the estimated coefficients. **denotes significance at the $5 \%$ level.

In phase III, in the EUA market, the 2nd-order lag return rate of the EUA futures market has an impact on the current return of $-0.14(\mathrm{~T}=-4.70)$, passing the significance test and showing that the EUA market has an autocorrelation and that the market reflects information slowly. In the CER market, the 1st-order lag return rate of the CER futures market has an impact on the current return of $-0.19(\mathrm{~T}=-6.21)$, and the 2nd-order lag return rate has an impact on the current return of $0.06(T=2.05)$, passing the significance test. These results show that the CER market has an autocorrelation and reflects its information quickly. We also find that compared with the EUA futures market, the CER futures market reflects more information.

The influence of the lag return rate of the EUA market on the current return rate of the CER market does not reach significance, indicating that the information in the EUA futures market has no effect on the CER market's return. Similarly, the impact of the lag return rate of the CER market on the current return rate of the EUA market does not reach significance, indicating that the information in the CER futures market has no effect on the EUA market's return.

Accordingly, we conclude that there is no return spillover between the EUA and CER markets in phase III. The result shows that, in phase III, investors cannot use the information on 
the EUA market to predict prices of the CER market, and that there is a trend of fragmentation between the EUA and CER markets. This phenomenon takes place because, in phase III, the European Commission has strictly restricted CER's substitution of EUA to reduce the correlation between the two markets. In addition, the global economic crisis and the European debt crisis allowed many unused carbon allowances at the end of the second phase of the EU ETS to be transferred to the third phase, resulting in a continuous oversupply in the EUA market and ultimately reducing the pressure on the industrial operators to reduce emissions. As a result, the volatility spillover effect of the EUA market on the CER market has been weakened to zero.

\subsubsection{Granger causality test}

Since the coefficients in the VAR model system are usually very large, the conclusions obtained by analyzing the model coefficient estimates are often not sufficiently accurate, and relying on tools such as the Granger test, impulse response function (IRF) and variance decomposition is necessary. The Granger test can be used to determine whether all hysteresis items of a variable have an effect on the current values of the other variables; thus, this test has been widely used (Geng et al., 2017; Kamdem et al., 2016).

Table 5 shows the results of the Granger causality test of RE and RC in phases II and III.

Table 5. Granger causality tests

Sample period $\quad$ Dependent variable Chi-square Prob.




\begin{tabular}{llll}
\hline Phase II & RE & 0.1964 & 0.9065 \\
\multirow{3}{*}{ Phase III } & RC & 18.7068 & $0.0001^{* * *}$ \\
& RE & 1.4901 & 0.4747 \\
& RC & 0.4408 & 0.8022 \\
\hline
\end{tabular}

Note: $* * *$ indicates the rejection of the null hypothesis at the $1 \%$ level of significance.

As shown in Table 5, in both phase II and phase III, the CER futures' return is not the Granger cause of the EUA futures' return. However, in phase II, at the significance level of $1 \%$, the EUA return is the granger cause of the CER return, which is consistent with the results above and the results reported by Koop and Tole (2013) and Nazifi (2013).

Therefore, we can draw the conclusion that in the return spillover effect of EUA and CER, EUA plays a dominant role, and the return spillover effect between the two markets has weakened to zero in phase III. The EUA market plays a leading role in the relationship between the two markets; one reason is that the main function of CER is to replace EUA to reduce the emission reduction costs of producers; the other reason is that, when compared with the CER market, the EUA market is more mature and larger in its market scale, thus contributing to a greater impact on the CER market.

\subsubsection{Impulse response function (IRF)}

Since the coefficients reflect only some dynamic relationships, it is impossible to capture the comprehensive dynamic relationship. Scholars tend to focus on the entire process by which one factor affects another. In this case, the dynamic influence of each factor can be reflected 
more comprehensively by drawing an IRF graph because the IRF captures the dynamic impact path.

According to the above analysis, the EUA and CER markets only have one-way return spillovers in phase II. Therefore, we only analyze the impulse response function graph of EUA and CER in phase II as shown in Fig. 7.

Response to Cholesky One S.D. (d.f. adjusted) Innovations+/-2 S.E.

Response of RE to RE

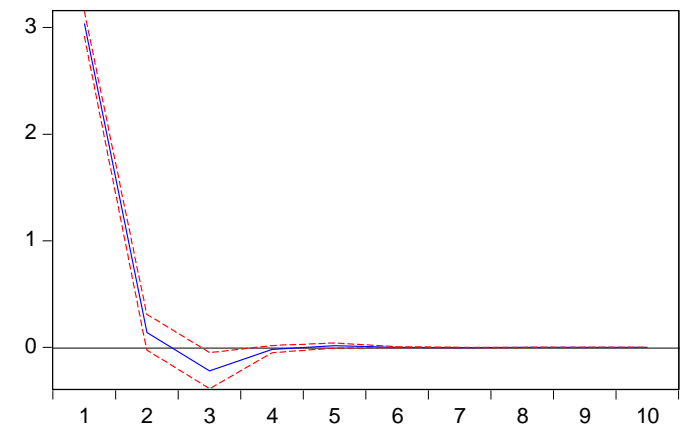

Response of $\mathrm{RC}$ to $\mathrm{RE}$

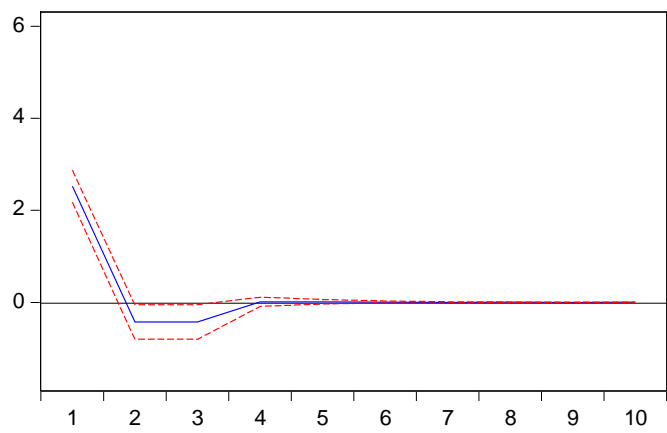

Response of RE to RC

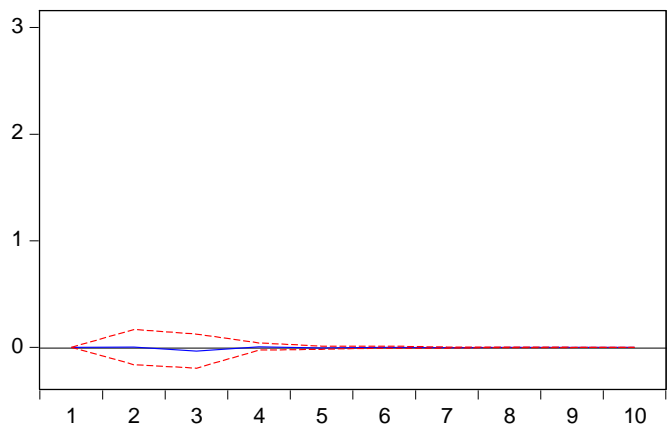

Response of $\mathrm{RC}$ to $\mathrm{RC}$

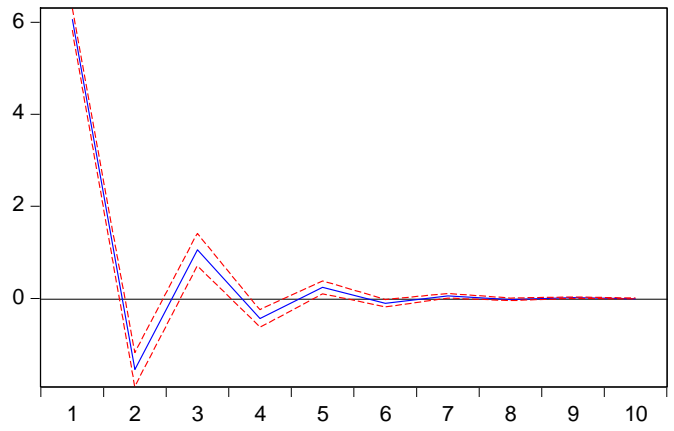

Fig. 7. The result of impulse response between EUA returns and CER returns in phase II

Figure 7 shows the impact of a standard deviation shock on the error term of EUA or CER return on the current value and future value of its own or of another market's rate of return. It also describes the time path of the response of EUA and CER returns to the returns of impulse shocks of 
their own market or another market. Among them, the abscissa axis represents the lag period of the shocks (one period is one day); the ordinate axis indicates the response degree of RE or RC; the solid line stands for the response of EUA or CER return to each shock; the dotted line shows the deviation band of positive and negative responses, which is twice of the standard deviation.

In phase II, when the EUA futures market is impacted by a standard deviation of its own, it can react quickly with a response degree of 3.04 in the first period, followed by a sudden drop. Additionally, the response in the second to third periods in the future is low with a response degree of 0.14 and -0.22 , respectively; then, it stabilizes to zero. In addition, before the third period, the effect of the EUA futures market on its own impact is positive, and the subsequent impact effect becomes negative, indicating that the effect of the EUA futures market on its own income sequence is first positive and then negative.

The impact of CER market information on the EUA market is neither timely nor sensitive. When the CER market has an impact on the EUA market, the EUA market's response degree is almost zero. This result shows that the CER market has no impact on the return of the EUA market, which is consistent with the results of the VAR model.

When the CER futures market is impacted by a standard deviation of the EUA futures market, it can respond quickly with a response degree of 2.52 in the first period, followed by a sharp fall to -0.43 in the second and third periods, and eventually stabilizes to zero. In addition, the impact of the EUA market on the CER returns in the first period is positive and then becomes negative, revealing that the impact of the EUA market on the CER market is first positive and 
then negative.

When the CER futures market is impacted by itself, it can react quickly with a response degree of 6.07 in the first period, followed by a sharp fall. The response degree in the second, third and fourth periods in the future is $-1.55,1.05$ and -0.44 , respectively. After the sixth period, the response degree tends to be zero.

The analysis result of the impulse response function shows that, in the second phase, when the EUA market receives a positive shock, the CER market will also be impacted accordingly. The influence of this shock will first be positive and then be negative, eventually, it will stabilize. This is because when the EUA market is shocked by a standard deviation, its return will rise significantly after one day. Since CER is a substitute for EUA, the return of CER will also increase. Afterwards, investors in the market will transfer a large amount of funds to the EUA market, which would cause the CER market to drop in liquidity and return in the next two days. However, when the CER market is shocked, the EUA market's return will not be affected.

\subsubsection{Variance decomposition}

Variance decomposition can decompose the variance of a variable in a VAR model into each perturbation term; thus, variance decomposition can be used to analyze the relative degree of the response of a variable to all other factors.

According to the above analysis, the EUA and CER markets only have one-way return spillovers in phase II. Therefore, we only analyze the variance decomposition of RE and RC in 
phase II as shown in Table 6.

Table 6. Results of the variance decomposition of EUA returns and CER returns in phase II

\begin{tabular}{llll|llll}
\hline \multicolumn{2}{l}{ Variance Decomposition of RE } & & \multicolumn{4}{l}{ Variance Decomposition of RC } \\
Period & S.E. & RE & RC & Period & S.E. & RE & RC \\
\hline 1 & 3.0370 & 100.0000 & 0.0000 & 1 & 6.5690 & 14.7539 & 85.2461 \\
2 & 3.0403 & 100.0000 & $5.33 \mathrm{E}-05$ & 2 & 6.7621 & 14.3216 & 85.6784 \\
3 & 3.0484 & 99.9868 & 0.0132 & 3 & 6.8571 & 14.3167 & 85.6833 \\
4 & 3.0484 & 99.9862 & 0.0138 & 4 & 6.8712 & 14.2581 & 85.7419 \\
5 & 3.0485 & 99.9861 & 0.0139 & 5 & 6.8753 & 14.2413 & 85.7587 \\
6 & 3.0485 & 99.9860 & 0.0140 & 6 & 6.8762 & 14.2377 & 85.7623 \\
7 & 3.0485 & 99.9860 & 0.0140 & 7 & 6.8764 & 14.2368 & 85.7632 \\
8 & 3.0485 & 99.9860 & 0.0140 & 8 & 6.8765 & 14.2366 & 85.7634 \\
9 & 3.0485 & 99.9860 & 0.0140 & 9 & 6.8765 & 14.2366 & 85.7634 \\
10 & 3.0485 & 99.9860 & 0.0140 & 10 & 6.8765 & 14.2366 & 85.7634 \\
\hline
\end{tabular}

The variance decomposition results of the EUA futures market show that the return rate of the EUA futures market is almost all from its own variance and not affected by the CER futures market, which is consistent with the results above.

Regarding the return of the CER market, the variance ratio derived from the EUA market return rate accounts for $14.75 \%$ in the first period and then gradually decreases and stabilizes at approximately $14.24 \%$. In comparison, the proportion of variance of $\mathrm{RC}$ in the first period is $85.25 \%$; then, this proportion gradually increases and finally stabilizes at approximately $85.76 \%$. 
In general, the variance of RC still accounts for the majority of the variance decomposition of its own market; thus, the CER futures market has an absolute advantage over its own price.

The variance decomposition results show that, in the second phase, the shock of the EUA market has a significant impact on the CER market, while the shock of the CER market has almost zero impact on the EUA market. This conclusion is consistent with the analysis of the impulse response function. Moreover, we also find that whether it is the EUA market or the CER market, the change in the current returns is mainly affected by the previous returns.

\subsection{BEKK-GARCH estimation of the volatility spillover effect}

According to Agren (2006) and Yu et al. (2019), the bivariate BEKK-GARCH model based on the VAR model can effectively study the volatility spillover effect between markets. The results of the VAR model revealed that there is only one-way return spillover effect of EUA on CER market in phase II of the EU ETS, while there was no return spillover effect between the EUA and CER markets in phase III. Therefore, we modify the mean equation of the BEKK-GARCH model as follows:

Conditional mean equation in phase II

$$
\begin{aligned}
& \mathrm{r}_{1 \mathrm{t}}=\mu_{1}+\delta_{11} \mathrm{r}_{1, \mathrm{t}-1}+\pi_{11} \mathrm{r}_{1, \mathrm{t}-2}+\varepsilon_{1 \mathrm{t}} \\
& \mathrm{r}_{2 \mathrm{t}}=\mu_{2}+\delta_{21} \mathrm{r}_{1, \mathrm{t}-1}+\delta_{22} \mathrm{r}_{2, \mathrm{t}-1}+\pi_{21} \mathrm{r}_{1, \mathrm{t}-2}+\pi_{22} \mathrm{r}_{2, \mathrm{t}-2}+\varepsilon_{2 \mathrm{t}}
\end{aligned}
$$

Conditional mean equation in phase III

$$
\mathrm{r}_{1 \mathrm{t}}=\mu_{1}+\delta_{11} \mathrm{r}_{1, \mathrm{t}-1}+\pi_{11} \mathrm{r}_{1, \mathrm{t}-2}+\varepsilon_{1 \mathrm{t}}
$$


$\mathrm{r}_{2 \mathrm{t}}=\mu_{2}+\delta_{22} \mathrm{r}_{2, \mathrm{t}-1}+\pi_{22} \mathrm{r}_{2, \mathrm{t}-2}+\varepsilon_{2 \mathrm{t}}$

where $r_{1}$ and $r_{2}$ are the returns of the EUA and CER markets at time $t$ and $\varepsilon_{1 \mathrm{t}}$ and $\varepsilon_{2 \mathrm{t}}$ are the error terms.

The results of the BEKK-GARCH(1,1) model of the EUA and CER futures markets in phase II are shown in Table 7. The results shown in Table 7 are divided into three parts. The first part shows the estimated results of the conditional mean equation. The second part shows the results of the conditional variance-covariance equation, which addresses the volatility spillover effects. The model diagnostics are presented at the end of the table; the Ljung-Box Q-statistics show that there are no serial correlations in the standardized residuals and the squared standardized residuals.

Table 7. Estimated results of the BEKK-GARCH model in phase II

\begin{tabular}{|c|c|c|}
\hline Coefficients & $\mathrm{RE}(\mathrm{i}=1)$ & $\mathrm{RC}(\mathrm{i}=2)$ \\
\hline \multicolumn{3}{|c|}{ Conditional mean equation } \\
\hline $\mathrm{RE}_{\mathrm{t}-1}$ & $0.0598(2.3446)^{* *}$ & $-0.0810(-2.5431)^{* *}$ \\
\hline $\mathrm{RE}_{\mathrm{t}-2}$ & $-0.0326(-1.2699)$ & $-0.0929(-2.5613) * *$ \\
\hline $\mathrm{RC}_{\mathrm{t}-1}$ & & $0.1473(4.7943)^{* * *}$ \\
\hline $\mathrm{RC}_{\mathrm{t}-2}$ & & $0.0953(2.9428) * * *$ \\
\hline Constant & $0.0181(0.3168)$ & $-0.0123(-0.2247)$ \\
\hline \multicolumn{3}{|c|}{ Conditional variance-covariance equation } \\
\hline $\mathrm{c}_{1 \mathrm{i}}$ & $0.3325(7.7980) * * *$ & \\
\hline $\mathrm{c}_{2 \mathrm{i}}$ & $0.2647(4.3817) * * *$ & $-0.2371(-8.0173) * * *$ \\
\hline
\end{tabular}




\begin{tabular}{lll}
\hline $\mathrm{a}_{1 \mathrm{i}}$ & $0.2817(12.8899) * * *$ & $-0.2062(-6.4093) * * *$ \\
$\mathrm{a}_{2 \mathrm{i}}$ & $-0.0416(-2.9749) * * *$ & $0.5357(16.2496) * * *$ \\
$\mathrm{~b}_{1 \mathrm{i}}$ & $0.9359(126.2331) * * *$ & $0.0607(4.2349) * * *$ \\
$\mathrm{~b}_{2 \mathrm{i}}$ & $0.0283(5.3506) * * *$ & $0.8788(66.9019) * * *$ \\
Model diagnostics & \\
$\mathrm{Q}(15)$ & 6.0766 & 14.2113 \\
$\mathrm{Q}^{2}(15)$ & 18.3380 & 10.0604 \\
Log-L & -5524.2932 & \\
Obs. & 1321 & \\
\hline
\end{tabular}

Note: The t-statistics are shown in parentheses. The numbers 1 and 2 represent the returns of the EUA market and CER market. ***,** and * denote significance at the $1 \%, 5 \%$ and $10 \%$ levels, respectively. $Q(15)$ and $Q^{2}(15)$ are the Ljung-Box Q-statistics of the standardized residuals and squared standardized residuals at lag 15.

In the estimate results of the conditional variance-covariance equation, the parameters $a_{11}, b_{11}, a_{22}$ and $b_{22}$ are all significant at the $5 \%$ level, indicating that both the EUA and CER markets have an impact conduction effect and a wave conduction effect on themselves. Thus, the volatilities of the two markets are influenced by their own past shocks and past volatilities. In addition, the estimated values of $b_{11}$ and $b_{22}$ are both greater than the estimated values of $a_{11}$ and $a_{22}$, suggesting that compared with historical shocks, historical volatilities have a more significant impact on the prices of the EUA market and CER market. This result can help us understand the transmission mechanism of carbon futures market risk to itself during the second phase. First, unexpected events in the EUA or CER market may stimulate higher 
volatilities of its own market prices. Second, volatilities in the EUA or CER market during a certain period may cause higher volatilities in the future.

The parameters $a_{12}$ and $b_{12}$ are both significant at the $5 \%$ level, indicating that the EUA market has a unidirectional impact conduction effect and a wave conduction effect on the CER market. Therefore, the fluctuation in the return rate of the EUA market will affect the fluctuation in the return rate of the CER market in both the long term and short term.

The parameters $a_{21}$ and $b_{21}$ are both significant at the 5\% level, indicating that the CER market has a unidirectional impact conduction effect and a wave conduction effect on the EUA market. Therefore, the fluctuation in the return rate of the CER market will affect the fluctuation in the return rate of the EUA market in both the long term and short term.

By comparing $a_{12}$ and $a_{21}$, we find that the effect of information from the EUA market to the CER market is greater than that from the CER market to the EUA market. By comparing $b_{12}$ and $b_{21}$, we conclude that the volatility of the EUA return rate has a greater effect on the fluctuation in the CER returns. Therefore, in phase II, the EUA and CER markets have volatility spillover effects, and the volatility spillover effect of EUA on CER is more significant.

In order to study the direction of the volatility spillover effect between the EUA and CER markets in phase II, we conduct Wald test on the parameters, as shown in Table 8. In the Wald test, the null hypothesis is $a_{i j}=b_{i j}=0$, indicating that there is no volatility spillover from market $i$ to market $j$, and the rejection of the null hypothesis indicates that there is volatility spillover from market $\mathrm{i}$ to market $\mathrm{j}$. 
Table 8. Wald test results of volatility spillover effect in phase II

\begin{tabular}{lll}
\hline Null hypothesis & Wald test statistic(Chi-Squared) & Prob. \\
\hline $\mathrm{H}_{0}: \mathrm{a}_{12}=\mathrm{b}_{12}=0$ & 43.2072 & 0.0000 \\
$\mathrm{H}_{0}: \mathrm{a}_{21}=\mathrm{b}_{21}=0$ & 32.7849 & 0.0000 \\
\hline
\end{tabular}

Note: The numbers 1 and 2 represent the returns of the EUA market and CER market.

According to table 8, the null hypotheses that "the EUA market does not have a one-way volatility spillover effect on the CER market" and "the CER market does not have a one-way volatility spillover effect on the EUA market" are rejected. These results indicate that there is a mutual volatility spillover effect between the EUA and CER markets in phase II. This result can help us understand the risk transmission mechanism between EUA and CER futures markets in phase II. First, unexpected events and volatilities in the EUA market can result in volatilities in the CER market. Second, unexpected events and volatilities in the CER market can also lead to volatilities in the EUA market. Since both EUA and CER can be used to fulfill the industrial operators' commitment to carbon emission reduction, when unexpected events or sharp volatilities occur in the EUA futures market, the increase in uncertainties and risks will drive industrial operators and investors to invest in CER futures, contributing to an increase in demand for CER futures, and resulting in volatilities in CER futures prices. When the risks of the CER market increases, the situation is similar.

The results of the BEKK-GARCH $(1,1)$ model of the EUA and CER futures markets in 
phase II are shown in Table 9. The Ljung-Box Q-statistics show that there are no serial correlations in the standardized residuals and squared standardized residuals.

Table 9. Estimated results of the BEKK-GARCH model in phase III

\begin{tabular}{|c|c|c|}
\hline Coefficients & $\mathrm{RE}(\mathrm{i}=1)$ & $\mathrm{RC}(\mathrm{i}=2)$ \\
\hline \multicolumn{3}{|c|}{ Conditional mean equation } \\
\hline $\mathrm{RE}_{\mathrm{t}-1}$ & $-0.0432(-1.3303)$ & \\
\hline $\mathrm{RE}_{\mathrm{t}-2}$ & $-0.1440(-5.0139)^{* * *}$ & \\
\hline $\mathrm{RC}_{\mathrm{t}-1}$ & & $-0.1157(-1.5083)$ \\
\hline $\mathrm{RC}_{\mathrm{t}-2}$ & & $0.0112(0.3127)$ \\
\hline Constant & $0.1032(1.7693)^{*}$ & $0.2501(0.8504)$ \\
\hline \multicolumn{3}{|c|}{ Conditional variance-covariance equation } \\
\hline$c_{1 i}$ & $0.2851(2.3701) * *$ & \\
\hline $\mathrm{c}_{2 \mathrm{i}}$ & $10.7532(41.1713) * * *$ & $-0.0005(-5.50 \mathrm{e}-05)$ \\
\hline $\mathrm{a}_{1 \mathrm{i}}$ & $0.3460(11.9467) * * *$ & $0.2010(2.2797) * *$ \\
\hline$a_{2 i}$ & $0.0019(0.2785)$ & $0.6390(10.1986) * * *$ \\
\hline $\mathrm{b}_{1 \mathrm{i}}$ & $0.9382(96.8015) * * *$ & $-0.2444(-1.6334)$ \\
\hline $\mathrm{b}_{2 \mathrm{i}}$ & $0.0024(0.2479)$ & $0.0312(0.2797)$ \\
\hline \multicolumn{3}{|c|}{ Model diagnostics } \\
\hline$Q(15)$ & 10.0865 & 10.0788 \\
\hline$Q^{2}(15)$ & 1.0335 & 0.0225 \\
\hline Log-L & -7084.9582 & \\
\hline Obs. & 1119 & \\
\hline
\end{tabular}

Note: The t-statistics are shown in parentheses. The numbers 1 and 2 represent the returns of the 44 
EUA market and CER market. ***,** and $*$ denote significance at the $1 \%, 5 \%$ and $10 \%$ levels, respectively. $\mathrm{Q}(15)$ and $\mathrm{Q}^{2}(15)$ are the Ljung-Box Q-statistics of the standardized residuals and squared standardized residuals at lag 15.

In the estimate results of the conditional variance-covariance equation, the parameters $a_{11}, b_{11}$ are both significant at the $5 \%$ level, indicating that the EUA market has an impact conduction effect and a wave conduction effect on itself. Thus, the volatility of the EUA market is influenced by its own past shocks and past volatilities. Additionally, the estimated values of $b_{11}$ is greater than the estimated values of $a_{11}$, indicating that compared with historical shocks, historical volatilities have a more significant impact on the prices of the EUA market. This result can help us understand the transmission mechanism of EUA futures market risk to itself during the third phase. First, unexpected events in the EUA market may stimulate higher volatilities of its market prices. Moreover, volatilities in the EUA during a certain period may cause higher volatilities in the future.

$a_{22}$ is significant at the $5 \%$ level, while $b_{22}$ is not significant, indicating that the CER market only has an impact conduction effect on itself. Thus, the volatility of the CER market returns is only influenced by its own past shocks. This result shows that unexpected events in the CER market may stimulate higher volatilities of its market price, while the historical volatilities of the CER market price has no effect on its market price.

$a_{12}$ is significant at the $5 \%$ level, indicating that the EUA market has a unidirectional impact conduction effect on the CER market. However, $b_{12}$ is not significant at the $5 \%$ level, 
and there is no wave conduction effect from the EUA market to CER market. Therefore, the EUA market affects the fluctuation in the return rate of the CER market only in the short term.

$a_{21}$ and $b_{21}$ are both not significant at the 5\% level, indicating that the fluctuation in the return rate of the EUA market is not affected by the CER market in both the long term and short term.

In order to study the direction of the volatility spillover effect between the EUA and CER markets in phase II, we conduct Wald test on the parameters, as shown in Table 10.

Table 10. Wald test results of volatility spillover effect in phase III

\begin{tabular}{lll}
\hline Null hypothesis & Wald test statistic(Chi-Squared) & Prob. \\
\hline $\mathrm{H}_{0}: \mathrm{a}_{12}=\mathrm{b}_{12}=0$ & 7.6271 & 0.0221 \\
$\mathrm{H}_{0}: \mathrm{a}_{21}=\mathrm{b}_{21}=0$ & 0.7806 & 0.6768 \\
\hline
\end{tabular}

Note: The numbers 1 and 2 represent the returns of the EUA market and CER market.

According to table 10, the Wald tests reject the null hypothesis that "the EUA market does not have a one-way volatility spillover effect on the CER market" but do not reject the null hypothesis that "the CER market does not have a one-way volatility spillover effect on the EUA market". This finding indicates that only the EUA market has a one-way volatility spillover effect on the CER market in phase III. This result can help us understand the risk transmission mechanism between EUA and CER futures markets in the third phase. In this phase, only unexpected events and volatilities in the EUA market can cause volatilities in the CER market. 
Unexpected events and volatilities in the CER market have no effect on the price of the EUA market. In other words, only the risks in the EUA market can be transmitted to the CER market, and investors can predict the risks in the CER market based on the risks in the EUA market, but they cannot predict the risks in the EUA market based on those in the CER market.

By comparing the estimated results in phase II and phase III, it can be observed that there is a two-way volatility spillover effect between the EUA and CER markets in phase II. However, in phase III, the volatility spillover effect between the two markets is weakened, and only the EUA market has a one-way volatility spillover effect on the CER market. This conclusion shows that, in the third phase, decrease in carbon emission reduction pressure caused by the oversupply of EUA and the restrictions on the use of CER by the European Commission have led to fragmentation of the EUA and CER markets, which reduces the investment risks of market participants.

\subsection{Impact of macroeconomic variables}

According to Nazifi (2013) and Conrad et al. (2012), economic activities affect the EUA and CER markets; to test the robustness of the main results, we added macroeconomic variables that might affect the market relationship between EUA and CER to the mean equation of the BEKK-GARCH model. These macroeconomic variables include the Euribor rate (three-month), the Citi Economic Surprise Index for the euro zone and the FTSE100 index. Among these variables, the three-month Euribor rate can accurately reflect the supply and demand of 
short-term funds in the financial market. The Citi Economic Surprise Index is a measure of the state of the economy; when this index is positive, the economy is performing better than widely expected, and when it is negative, the economy is performing worse than expected. In addition, the FTSE100 index measures economic strength and development. Because all the three macroeconomic variables are non-stationary series in phase II and phase III, we use their first difference (dFTSE100, dEURIBOR and dCESIEUR) in the analysis, as shown in Table A.2. The estimated results are shown in Table 11-13, and the results are consistent with the study above. We can also find that the returns of the EUA and CER markets are affected by the stock market and the Euribor rate in Phase II; however, the impact of the Euribor rate on the carbon market weakens to zero in Phase III.

Table 11. Estimated results of the BEKK-GARCH model with macroeconomic variables in phase II

\begin{tabular}{lll}
\hline Coefficients & $\mathrm{RE}(\mathrm{i}=1)$ & $\mathrm{RC}(\mathrm{i}=2)$ \\
\hline Conditional mean equation & & \\
$\mathrm{RE}_{\mathrm{t}-1}$ & $0.0575(2.2897) * *$ & $-0.0656(-3.4041) * * *$ \\
$\mathrm{RE}_{\mathrm{t}-2}$ & $-0.0242(-1.0119)$ & $-0.0816(-2.4653) * *$ \\
$\mathrm{RC}_{\mathrm{t}-1}$ & & $0.1167(6.0131) * * *$ \\
$\mathrm{RC}_{\mathrm{t}-2}$ & & $0.0915(3.1898) * * *$ \\
Constant & $0.0043(0.0817)$ & $-0.0135(-0.2652)$ \\
$\mathrm{dFTSE} 100$ & $0.0076(9.1711) * * *$ & $0.0058(6.7896) * * *$ \\
\hline
\end{tabular}




\begin{tabular}{lll}
\hline dEURIBOR & $10.0178(3.2156) * * *$ & $8.2640(2.6961) * * *$ \\
dCESIEUR & $-0.0026(-0.5754)$ & $-0.0022(-0.4788)$ \\
Conditional variance-covariance equation & \\
$\mathrm{c}_{1 \mathrm{i}}$ & $0.3423(7.0610) * * *$ & \\
$\mathrm{c}_{2 \mathrm{i}}$ & $0.2746(3.5028) * * *$ & $0.2152(8.0763) * * *$ \\
$\mathrm{a}_{1 \mathrm{i}}$ & $0.2094(9.1595) * * *$ & $-0.2467(-8.2173) * * *$ \\
$\mathrm{a}_{2 \mathrm{i}}$ & $0.0669(4.3012) * * *$ & $0.5872(20.0061) * * *$ \\
$\mathrm{~b}_{1 \mathrm{i}}$ & $0.9831(135.1471) * * *$ & $0.0874(6.4482) * * *$ \\
$\mathrm{~b}_{2 \mathrm{i}}$ & $-0.0308(-5.5405) * * *$ & $0.8505(67.0600) * * *$ \\
$\mathrm{Model} \mathrm{diagnostics}^{*}$ & \\
$\mathrm{Q}(15)$ & 5.6308 & 10.5560 \\
$\mathrm{Q}^{2}(15)$ & 19.9368 & 8.9458 \\
Log-L & -5499.9956 & \\
Obs. & 1321 & \\
\hline
\end{tabular}

Note: The t-statistics are shown in parentheses. The numbers 1 and 2 represent the returns of the EUA market and CER market. ***,** and * denote significance at the $1 \%, 5 \%$ and $10 \%$ levels, respectively. $Q(15)$ and $Q^{2}(15)$ are the Ljung-Box Q-statistics of the standardized residuals and squared standardized residuals at lag 15.

Table 12. Estimated results of the BEKK-GARCH model with macroeconomic variables in phase III

\begin{tabular}{lll}
\hline Coefficients & RE (i=1) & RC (i=2)
\end{tabular}

Conditional mean equation 


\begin{tabular}{lll}
\hline $\mathrm{RE}_{\mathrm{t}-1}$ & $-0.0589(-1.8292) *$ & \\
$\mathrm{RE}_{\mathrm{t}-2}$ & $-0.1431(-4.6453) * * *$ & \\
$\mathrm{RC}_{\mathrm{t}-1}$ & & $-0.1051(-1.3159)$ \\
$\mathrm{RC}_{\mathrm{t}-2}$ & & $0.0166(0.4534)$ \\
Constant & $0.1183(1.8718) *$ & $0.3045(1.0422)$ \\
$\mathrm{dFTSE} 100$ & $0.0040(4.2276) * * *$ & $0.0050(0.8441)$ \\
$\mathrm{dEURIBOR}$ & $12.4816(0.6186)$ & $30.6725(0.2426)$ \\
$\mathrm{dCESIEUR}$ & $0.0215(1.6185)$ & $0.0524(0.9135)$ \\
Conditional variance-covariance equation & & \\
$\mathrm{c}_{1 \mathrm{i}}$ & $-0.2434(-2.1519) * *$ & \\
$\mathrm{C}_{2 \mathrm{i}}$ & $-10.7480(-43.9261) * * *$ & $0.0018(1.78 \mathrm{e}-04)$ \\
$\mathrm{a}_{1 \mathrm{i}}$ & $0.3430(12.3959) * * *$ & $0.2045(2.2146) * *$ \\
$\mathrm{a}_{2 \mathrm{i}}$ & $0.0021(0.3296)$ & $0.6430(10.2263) * * *$ \\
$\mathrm{~b}_{1 \mathrm{i}}$ & $0.9405(110.7887) * * *$ & $-0.2131(-1.6595) *$ \\
$\mathrm{~b}_{2 \mathrm{i}}$ & $0.0029(0.3100)$ & $0.0426(0.3877)$ \\
$\mathrm{Model}$ & & \\
$\mathrm{Q}(15)$ & 1119 & 9.8159 \\
$\mathrm{Q}^{2}(15)$ & & \\
Log-L & & \\
Obs. & -7074.5864 & \\
\hline & & \\
\hline
\end{tabular}

Note: The t-statistics are shown in parentheses. The numbers 1 and 2 represent the returns of the EUA market and CER market. ${ }^{* *}, * *$ and $*$ denote significance at the $1 \%, 5 \%$ and $10 \%$ levels, respectively. $Q(15)$ and $Q^{2}(15)$ are the Ljung-Box Q-statistics of the standardized residuals and squared standardized residuals at lag 15. 
Table 13. Wald test results of volatility spillover effect with macroeconomic variables

\begin{tabular}{lll}
\hline Null hypothesis & \multicolumn{2}{l}{ Wald test statistic(Chi-Squared) } \\
\cline { 2 - 3 } & Phase II & Phase III \\
\hline $\mathrm{H}_{0}: \mathrm{a}_{12}=\mathrm{b}_{12}=0$ & $68.7552 * * *$ & $7.3231^{* *}$ \\
& $(0.0000)$ & $(0.0260)$ \\
$\mathrm{H}_{0}: \mathrm{a}_{21}=\mathrm{b}_{21}=0$ & $30.8604 * * *$ & 1.1308 \\
& $(0.0000)$ & $(0.5681)$ \\
\hline
\end{tabular}

Note: The $\mathrm{P}$ values are shown in parentheses. The numbers 1 and 2 represent the returns of the EUA market and CER market. $* * *$ and $* *$ denote significance at the $1 \%$ and $5 \%$ levels, respectively.

\section{Conclusions and policy implications}

EUA and CER are two important components of the EU ETS; they represent the carbon price of European countries and developing countries respectively. Therefore, studying the relationship between these two markets can help managers understand the operating rules of the carbon market and provide a basis for the unified management of the carbon market. Unlike existing literature, this paper mainly studies the transmission mechanism of volatility information between the EUA and CER markets, and extends the study to the third phase of the EU ETS.

The volatility spillover effect represents the information flow between markets, and its 
essence is the transmission of risks between markets. Studying the volatility spillover effects between the EUA and CER markets will help investors and managers in the carbon market understand the internal information and risk transmission rules of the carbon market, and make scientific and reasonable decisions to better respond to the risk of carbon price volatilities. In addition, comparing the changes in the volatility spillover effects between the EUA and CER markets in the second and third phases of the EU ETS can help to analyze the impact of changes in the EU ETS policies and the environment on the internal relations of the carbon market, providing experience and reference for the construction of the EU and other countries' carbon markets.

In this paper, we first conduct a breakpoint unit root test on the returns of EUA and CER futures. Consequently, we find that the market structure of the EUA and CER markets has changed once the EU ETS entered the third phase with a four-month delay, indicating that the policy and environmental changes in different phases of EU ETS have an impact on both the EUA and CER markets. Based on this result, we analyze the return spillovers and volatility spillovers of these two markets in different phases according to the structural break dates.

In order to make the results more accurate, we refer to the method of Agren (2006) and modify the BEKK-GARCH model based on the return spillover effect between the EUA and CER markets. Through methods such as VAR model, Granger causality test, impulse response function and variance decomposition, we find that only EUA has a unidirectional effect on CER in phase II, and in phase III, there are no return spillovers between the two markets. We also find that both the 
EUA market and the CER market are affected by themselves, but the CER market reflects more frequently and rapidly on its own information.

Then, we use the improved GARCH-BEKK model to study the volatility spillover effect between the EUA and CER markets. The conclusion is that there is a two-way volatility spillover effect between the EUA and CER markets in phase II. In both the short-term and long-term, the volatilities of EUA and CER market returns affect each other, and the EUA market has a more significant volatility spillover effect on the CER market. However, in phase III, only the EUA market has a unidirectional volatility spillover effect on the CER market, and the volatilities of the EUA market return affect the volatilities of the CER market return in the short term.

Finally, we verify the robustness of the results through robustness tests.

In general, we find that the EUA and CER markets have an asymmetric volatility spillover effect and that the EUA market dominates in the information transmission process. Furthermore, we also find that, after EU ETS enters the third phase, the volatility spillover effect between the EUA and CER markets becomes weaker, and that only the EUA market has a unidirectional volatility spillover effect on the CER market.

Our conclusion confirms the hypothesis of this paper, which infers that, within the carbon market, information flows mainly from the EUA market to the CER market. In other words, shocks in the EUA market will result in price volatilities in the CER market, but the risk of the CER market is less capable of predicting EUA market risk. Even in the phase III of the EU ETS, the 
risk of the EUA market cannot be predicted based on the CER market. Our conclusion also confirms that changes in policies and the environment at different phases of the EU ETS will affect the internal relationship of the carbon market. As the EU ETS entered the third phase, the European Commission has limited the substitution of CER for EUA more strictly; only CER from least developed regions that is accepted by all EU Member States can be used as a substitute for EUA in phase III. Moreover, international carbon emission reduction requirements have become more relaxed, making the EUA and CER markets more fragmented.

Our research has implications for both investors and carbon market managers. From the perspective of carbon market investors, on the one hand, the volatility spillover effect of EUA and CER markets in the third phase of EU ETS has been significantly reduced, indicating that the market risks faced by carbon market investors have been reduced. Thus, they can use EUA and CER futures to design appropriate hedging strategies. On the other hand, since the EUA market still has a risk spillover effect on the CER market, investors in CDM projects need to pay attention to preventing the EUA market from adding input risk to the CER market. Investors should also focus on the volatility of the EUA market price and make a more accurate prediction of the volatility of the CER price, so that they may adjust investment strategies in time to deal with the risk spillover of the EUA market.

For carbon market managers, due to the asymmetric volatility spillover effect between the EUA market and the CER market, changes in the EUA market's return rate are likely to increase 
the risk of price volatilities in the CER market. Therefore, when formulating relevant policies, managers should consider the impact of EUA market volatilities on the CER market, and establish a risk prevention and management mechanism for the carbon market to better manage spillover effects between markets and reduce risks. Second, our research finds that changes in carbon market policies and the international carbon emission reduction environment have a significant impact on the relationship between EUA and CER markets. Therefore, managers need to consider the impact of policy changes on the internal relationship of the carbon market when formulating policies. At the same time, managers can also manage the relationship between the EUA market and the CER market by formulating relevant policies.

In summary, this article mainly studies the volatility spillover effect between EUA and CER markets, and confirms that changes in policies and the international carbon emission reduction environment during different phases of the EU ETS have a significant impact on the relationship between EUA and CER markets. Our research helps investors and managers in the carbon market make reasonable decisions. However, this paper also has limitations. First, the research object of this paper is the EU carbon futures market, the relationship between the EUA and CER spot markets needs to be further studied. Second, this paper does not propose specific risk management methods based on the results of empirical research. In future research, we will further study the risks of the carbon market and propose feasible investment portfolio plans. 


\section{Acknowledgements}

The authors acknowledge the valuable comments and suggestions provided by our colleagues.

The authors are grateful to the anonymous reviewers, whose comments have helped us improve the manuscript.

\section{Funding}

This research is partially funded by the National Natural Science Foundation of China (71473010), Capacity Building of Science and Technology Innovation Services (Research Category) in 2019-Beijing Basic Research Business Expenses in Beijing University of Technology (011000546320503) and (011000546320532).

\section{Declarations of interest}

The authors declare that they have none conflicts of interest.

\section{Data availability}

The Data availability come from Table A.1. Data source.

\section{Appendix}

Table A.1. Data source

\begin{tabular}{lll}
\hline Variables & Content & Data source
\end{tabular}




\begin{tabular}{|c|c|c|}
\hline EUA price & $\begin{array}{l}\text { European Union allowance futures } \\
\text { price (settle price) }\end{array}$ & Wind Database (www.wind.com.cn) \\
\hline CER price & $\begin{array}{l}\text { Certified emissions reduction } \\
\text { futures price (settle price) }\end{array}$ & Wind Database (www.wind.com.cn) \\
\hline FTSE100 & FTSE100 index & Wind Database (www.wind.com.cn) \\
\hline EURIBOR & Three-month Euribor rate & Wind Database (www.wind.com.cn) \\
\hline CESIEUR & $\begin{array}{l}\text { Citi Economic Surprise Index for } \\
\text { the euro zone }\end{array}$ & Wind Database (www.wind.com.cn) \\
\hline
\end{tabular}

Table A.2. The results of the augmented Dickey-Fuller Unit Root Test

\begin{tabular}{lllll}
\hline Sample period & Variable & t-Statistics & Prob. & Result \\
\hline Phase II & FTSE100 & -2.7368 & 0.2218 & Non-stationary \\
& EURIBOR & -1.4846 & 0.8347 & Non-stationary \\
& CESIEUR & -2.3699 & 0.3952 & Non-stationary \\
& dFTSE100 & -37.4634 & 0.0000 & Stationary \\
& dEURIBOR & -8.2199 & 0.0000 & Stationary \\
Phase III & dCESIEUR & -33.2408 & 0.0000 & Stationary \\
& FTSE100 & -2.4128 & 0.3726 & Non-stationary \\
& EURIBOR & -2.0611 & 0.5664 & Non-stationary \\
& CESIEUR & -2.4911 & 0.3325 & Non-stationary \\
& dFTSE100 & -32.5889 & 0.0000 & Stationary \\
& dEURIBOR & -11.0094 & 0.0000 & Stationary \\
& dCESIEUR & -33.6299 & 0.0000 & Stationary \\
\hline
\end{tabular}

Note: Trend and intercept are included in the test equation, and the lag length is determined according to the Schwarz criterion (SC). 


\section{References}

Agren, M., 2006. Does oil price uncertainty transmit to stock markets? Working Paper No. 2006:23.Department of Economics,Uppsala University.

Arouri, M.E.H., Jawadi, F., Nguyen, D.K., 2012. Nonlinearities in carbon spot-futures price relationships during Phase II of the EU ETS. Econ. Model. 29, 884-892. https://doi.org/10.1016/j.econmod.2011.11.003.

Balc1lar, M., Demirer, R., Hammoudeh, S., Nguyen, D.K., 2016. Risk spillovers across the energy and carbon markets and hedging strategies for carbon risk. Energy Econ. 54, 159172. https://doi.org/10.1016/j.eneco.2015.11.003.

Chai, Z., Zhou, P., 2018. The Minimum-CVaR Strategy with Semi-parametric Estimation in Carbon Market Hedging Problems. Energy Econ. 76, 64-75. https://doi.org/10.1016/j.eneco.2018.09.024.

Chevallier, J., 2010a. A Note on cointegrating and vector autoregressive relationships between CO2 allowances spot and futures prices. Econ. Bull. 30, 1564-1584.

Chevallier, J., 2010b. EUAs and CERs: Vector Autoregression, Impulse Response Function and Cointegration Analysis. Econ. Bull. 30, 558-576.

Chevallier, J., 2011. Anticipating correlations between EUAs and CERs: a Dynamic Conditional Correlation GARCH model. Econ. Bull. 31, 255-272.

Conrad, C., Rittler, D., Rotfuß, W., 2012. Modeling and explaining the dynamics of European Union allowance prices at high-frequency. Energy Econ. 34, 316-326. 
https://doi.org/10.1016/j.eneco.2011.02.011.

Cummins, M., 2013. EU ETS market interactions: the case for multiple hypothesis testing approaches. Appl. Energy 111, 701-709. https://doi.org/10.1016/j.apenergy.2013.05.032.

Diebold, F.X., Yilmaz, K., 2012. Better to give than to receive: predictive directional measurement of volatility spillovers. Int. J. Forecast. 28, 57-66. https://doi.org/10.1016/j.ijforecast.2011.02.006.

Dutta, A., 2018. Modeling and forecasting the volatility of carbon emission market: The role of outliers, time-varying jumps and oil price risk. J. Clean. Prod. 172, 2773-2781. https://doi.org/10.1016/j.jclepro.2017.11.135.

Engle, R.F., Kroner, K.F., 1995. Multivariate simultaneous generalized ARCH. Econ. Theory 11, 122-150. https://doi.org/10.1017/s0266466600009063.

Fan, Y., Jia, J.-J., Wang, X., Xu, J.-H., 2017. What policy adjustments in the EU ETS truly affected the carbon prices? Energy Policy. 103, 145-164. http://dx.doi.org/10.1016/j.enpol.2017.01.008.

Feria-Domínguez, J.M., Rodriguez-Carrillero, D., Guerra-Martinez, J.C., 2018. Measuring the risk-adjusted performance of $\mathrm{CO} 2$ emission markets: evidence from SENDECO2. Util. Policy 50, 124-132. https://doi.org/10.1016/j.jup.2017.12.001.

Geng, J.-B., Ji, Q., Fan, Y., 2017. The relationship between regional natural gas markets and crude oil markets from a multi-scale nonlinear granger causality perspective. Energy Econ. 67, 98-110. https://doi.org/10.1016/j.eneco.2017.08.006. 
Green, R., Larsson, K., Lunina, V., Nilsson, B., 2018. Cross-commodity news transmission and volatility spillovers in the German energy markets. J. Bank. Finance 95, 231-243. https://doi.org/10.1016/j.jbankfin.2017.10.004.

Gürler, Ü., Yenigün, D., Çağlar, M., Berk, E., 2016. On the modeling of $\mathrm{CO}_{2}$ EUA and CER prices of EU-ETS for the 2008-2012 period. Appl. Stoch. Models Bus. Ind. 32, 375-395. https://doi.org/10.1002/asmb.2154.

Hammoudeh, S., Lahiani, A., Nguyen, D.K., Sousa, R.M., 2015. An empirical analysis of energy cost pass-through to $\mathrm{CO}_{2}$ emission prices. Energy Econ. 49, 149-156. https://doi.org/10.1016/j.eneco.2015.02.013.

Han, L., Jin, J., Wu, L., Zeng, H., 2019. The volatility linkage between energy and agricultural futures markets with external shocks. Int. Rev. Financ. Anal. https://doi.org/10.1016/j.irfa.2019.01.011.

Hegerty, S.W., 2016. Commodity-price volatility and macroeconomic spillovers: evidence from nine emerging markets. N. Am. J. Econ. Finance 35, 23-37. https://doi.org/10.1016/j.najef.2015.10.014.

Kamdem, J.S., Nsouadi, A., Terraza, M., 2016. Time-frequency analysis of the relationship between EUA and CER carbon markets. Environ. Model. Assess. 21, 279-289. https://doi.org/10.1007/s10666-015-9478-y.

Kanamura, T., 2016. Role of carbon swap trading and energy prices in price correlations and volatilities between carbon markets. Energy Econ. 54, 204-212. 
https://doi.org/10.1016/j.eneco.2015.10.016.

Khalfaoui, R., Boutahar, M., Boubaker, H., 2015. Analyzing volatility spillovers and hedging between oil and stock markets: evidence from wavelet analysis. Energy Econ. 49, 540549. https://doi.org/10.1016/j.eneco.2015.03.023.

Koop, G., Tole, L., 2013. Modeling the relationship between European carbon permits and certified emission reductions. J. Empir. Finance 24, 166-181. https://doi.org/10.1016/j.jempfin.2013.10.005.

Mansanet-Bataller, M., Chevallier, J., Hervé-Mignucci, M., Alberola, E., 2011. EUA and sCER phase II price drivers: unveiling the reasons for the existence of the EUA-sCER spread. Energy Policy 39, 1056-1069. https://doi.org/10.1016/j.enpol.2010.10.047.

Medina, V., Pardo, A., 2013. Is the EUA a new asset class? Quant. Finance 13, 637-653. https://doi.org/10.1080/14697688.2012.691985.

Nasreen, S., Tiwari, A.K., Eizaguirre, J.C., Wohar, M.E., 2020. Dynamic connectedness between oil prices and stock returns of clean energy and technology companies. J. Clean. Prod. 260, 121015. https://doi.org/10.1016/j.jclepro.2020.121015.

Nazifi, F., 2013. Modelling the price spread between EUA and CER carbon prices. Energy Policy 56, 434-445. https://doi.org/10.1016/j.enpol.2013.01.006.

Nazlioglu, S., Erdem, C., Soytas, U., 2013. Volatility spillover between oil and agricultural $\begin{array}{llll}\text { commodity } & \text { markets. }\end{array}$ https://doi.org/10.1016/j.eneco.2012.11.009. 
Rajalingam, M., Srivastava, A., 2020. Rational Hybrid Analytical Model for Steel Pipe Rack Quantification in Oil \& Gas Industries. Civil Engineering Journal. 6, 649-658. http://dx.doi.org/10.28991/cej-2020-03091497.

Reboredo, J.C., 2014. Volatility spillovers between the oil market and the European Union carbon emission market. Econ. Model. 36, 229-234. http://dx.doi.org/10.1016/j.econmod.2013.09.039.

Rittler, D., 2012. Price discovery and volatility spillovers in the European Union emissions trading scheme: a high-frequency analysis. J. Bank. Finance 36, 774-785. https://doi.org/10.1016/j.jbankfin.2011.09.009.

Ross, S.A., 1989. Information and Volatility: The No-Arbitrage Martingale Approach to Timing $\begin{array}{lllll}\text { and } & \text { Resolution } & \text { Irrelevancy. }\end{array}$ http://dx.doi.org/10.1111/j.1540-6261.1989.tb02401.x

Salisu, A., Oloko, T., 2015. Modeling oil price-US stock nexus: A VARMA-BEKK-AGARCH approach. Energy Econ. 50, 1-12. https://doi.org/10.1016/j.eneco.2015.03.031.

Sarwar, S., Khalfaoui, R., Waheed, R., Dastgerdi, H.G., 2019. Volatility spillovers and hedging: evidence from Asian oil-importing countries. Resour. Policy 61, 479-488. https://doi.org/10.1016/j.resourpol.2018.04.010.

Seyedimany, A., 2019. Stock Price Reactions on NASDAQ Stock Exchange for Special Dividend Announcements. Emerging Science Journal. 3, 382-388. http://dx.doi.org/10.28991/esj-2019-01200. 
Shen, Y., Shi, X., Variam, H.M.P., 2018. Risk transmission mechanism between energy markets: a VAR for VaR approach. Energy Econ. 75, 377-388. https://doi.org/10.1016/j.eneco.2018.08.027.

Sousa, R., Aguiar-Conraria, L., Soares, M.J., 2014. Carbon financial markets: a time-frequency analysis of $\mathrm{CO} 2$ prices. Phys. A: Stat. Mech. Appl. 414, 118-127. https://doi.org/10.1016/j.physa.2014.06.058.

Tang, B.-J., Gong, P.-Q., Shen, C., 2017. Factors of carbon price volatility in a comparative analysis of the EUA and sCER. Ann. Oper. Res. 255, 157-168. https://doi.org/10.1007/s10479-015-1864-y.

Uddin, G.S., Hernandez, J.A., Shahzad, S.J.H., Hedström, A., 2018. Multivariate dependence and spillover effects across energy commodities and diversification potentials of carbon assets. Energy Econ. 71, 35-46. https://doi.org/10.1016/j.eneco.2018.01.035.

Wu, H., Li, S., 2013. Volatility spillovers in China's crude oil, corn and fuel ethanol markets. Energy Policy 62, 878-886. https://doi.org/10.1016/j.enpol.2013.07.026.

Wu, Q., Wang, M., Tian, L., 2020. The market-linkage of the volatility spillover between traditional energy price and carbon price on the realization of carbon value of emission reduction behavior. J. Clean. Prod. 245, 118682. https://doi.org/10.1016/j.jclepro.2019.118682.

Yu, L., Zha, R., Stafylas, D., He, K., Liu, J., 2019. Dependences and volatility spillovers between the oil and stock markets: new evidence from the copula and VAR-BEKK-GARCH 
models. Int. Rev. Financ. Anal. https://doi.org/10.1016/j.irfa.2018.11.007.

Zeng, S., Nan, X., Liu, C., Chen, J., 2017. The response of the Beijing carbon emissions allowance price (BJC) to macroeconomic and energy price indices. Energy Policy 106, 111-121. https://doi.org/10.1016/j.enpol.2017.03.046.

Zhang, Y.-J., Sun, Y.-F., 2016. The dynamic volatility spillover between European carbon trading market and fossil energy market. J. Clean. Prod. 112, 2654-2663. https://doi.org/10.1016/j.jclepro.2015.09.118.

Zhu, B., Huang, L., Yuan, L., Ye, S., Wang, P., 2020. Exploring the Risk Spillover Effects between Carbon Market and Electricity Market: A Bidimensional Empirical Mode Decomposition Based Conditional Value at Risk Approach. Int. Rev. Econ. Finance. 67, 163-175. https://doi.org/10.1016/j.iref.2020.01.003. 